Kuntzman, J., Kendall, B. E., Gaines, S., Genetti, C., \& Hegarty, M. (2021, July 1). Facilitating Interdisciplinary Dialog in Research and Teaching: A roadmap for providing timely, needs-based project support. https://doi.org/10.35542/osf.io/wu56t

\title{
Facilitating Interdisciplinary Dialog in Research and Teaching: A roadmap for providing timely, needs-based project support
}

\author{
Joshua Kuntman, Bruce E. Kendall, Steven D. Gaines, Carol Genetti \& Mary Hegarty \\ University of California, Santa Barbara
}

\begin{abstract}
Interdisciplinary research and teaching is intellectually rewarding and practically challenging for the same reason: integrating disciplinary perspectives and methods requires all involved to study and communicate beyond the bounds of their expertise. Project facilitators may offer crucial support in such situations, anticipating needs before struggles arise and managing communication logistics while participants attend to the content of those dialogs. UCSB's Crossroads program has tested a series of facilitated dialog activities with several interdisciplinary groups. We have found that such interventions - when tailored and timed responsively to fit each project's unique goals and structure - can help groups to transition more efficiently and cohesively through the stages of interdisciplinary collaboration. Examples and explanations of such types of interventions are provided.
\end{abstract}

\section{Purpose}

Leveraging the expertise of multiple disciplines to address complex real-world issues is difficult but important work. In this era of entwined ecological, social, technological, and ethical issues, specialists must combine and coordinate knowledge-bases and skill-sets to produce more nuanced understandings and effective solutions. Research and publication trends show the notable impact of interdisciplinary collaborations on modern scholarship (Begg \& Vaughn, 2011; Chen, Arsenault, \& Lariviere, 2015), while professional hiring trends show employers' desire for individuals who know how to communicate and problem-solve creatively in diverse work groups (NASEM, 2018).

The structure and culture of academic institutions often presents logistical boundaries to collaboration (Boden, Borrego, \& Newswander, 2011). Furthermore, individuals in interdisciplinary collaborations face deep intellectual and social-emotional challenges in figuring out how to work productively with people who think, speak, and carry disciplinary expertise that is unfamiliar to them (Boix Mansilla, Lamont, \& Sato, 2016; Graybill et al., 2006; Turner et al., 2015; Welch-Devine et al., 2014).

The Crossroads Program at the University of California, Santa Barbara, has been working since 2012 to facilitate interdisciplinary research and teaching across campus by supporting one-year projects that produce interdisciplinary scholarship, bring that content into undergraduate courses, and give doctoral students leadership experience in such collaborations. The program's first round of projects yielded promising results in interdisciplinary research and teaching, but also a clear message from participants that structured facilitation would have yielded more efficient and productive collaborations (see also, Gamse, Espinosa \& Roy, 2013; Gilkey \& Earp, 2006).

Consequently, between 2017 and 2019, Crossroads has tested and refined interventions lead by a facilitator and aimed at bolstering dialogs in interdisciplinary research-into-teaching projects. These 
activities are informed by research about interdisciplinary collaboration and by ongoing feedback from projects, then tailored to address specific groups' unique needs and goals.

\section{Theoretical Framework}

Interdisciplinary research and integrative teaching rely on analogous strategies for overcoming communication barriers. Studies of collaborative and cross-disciplinary group dynamics (Derrick et al., 2011; Felt et al., 2013) consistently emphasize two challenging areas that participants must work through to productively integrate their approaches: intellectual diversity and relational asymmetry. That is, individuals in any given interdisciplinary group are going to be experts in different fields and subfields, meaning that any time they look together at X piece of data or discuss Y analytic method, (1) some of them are going to be more - or differently_familiar with that piece of the project, and (2) the group members who need to assume the 'teacher' or 'learner' roles are going to trade at various points in that project, as they work toward shared understandings and plans of action.

These challenges are common and natural in interdisciplinary endeavors, due to the progressive character of expertise. All members of disciplines begin as novices, gradually learning by participating in activities and conversations about how to behave as experts (Tuomi-Grohn, Engestrom, \& Young, 2003). Disciplinary "threshold concepts" inform the way its experts think, speak, and organize information into larger frameworks of understanding; these personal transformations are often difficult to progress through, irreversible once achieved, and have boundaries where they meet other field's threshold concepts (Meyer \& Land, 2006). This means that while individuals may have skilled intuition within the bounds of their field (Kahneman \& Klein, 2009), they can also quickly become uncomfortable and confused when encountering other disciplines' ideas, terminologies, and practices.

Thus the path toward integrating groups' thought, language, and actions relies on intentional and explicit dialogs, whether in classrooms with less practically experienced participants or in research cohorts with less ideologically flexible ones. A designated facilitator is important in such work because mutual understanding, responsibility sharing, full participation, and inclusive solutions are difficult to manage for participants who are subject to their own motivated biases (Kaner 2014). Facilitators can help manage interactions among participants, moving group dialogs toward common goals (Hmelo-

Silver \& Barrows, 2006). In collaborations among experts, such methodical exchanges generally emphasize communicating directly and concretely all participants' motives, values, techniques, and knowledge (Fisher et al., 2015). The "Toolbox" method, for example, offers probing questions designed to help groups recognize differences in participants' philosophies, increase interest in each other's disciplinary approaches, and identify shared ideas (Eigenbrode et al., 2007; Donovan, O’Rourke, \& Looney, 2015).

\section{Methods and Data}

In line with other research on integrative graduate education, we examined the efficacy of our program model using a descriptive and qualitative case study methodology (e.g., Nielsen-Pincus et al 2007; Gamse, Espinosa \& Roy 2013; Turner et al. 2015). During Phase 1 of Crossroads (Appendix A: Table I), each project's lead faculty were given prompts to address in writing reports about their group's learning experiences, challenges, and outcomes. Many of these faculty were also interviewed in focus groups after projects concluded. These faculty self-reports, plus a summary report of their interviews, were then textually analyzed to (a) describe the structure of projects in terms of stages and tasks, and to (b) serve as a needs assessment (Royse, Staton-Tindall, Badger \& Webster, 2009) for future projects. This Phase 1 synthesis highlighted themes across projects regarding when collaborative challenges 
arose, what factors intensified or alleviated those challenges, and types of support desired (Table 1). 
Table 1: Interdisciplinary groups' self-reported needs for preparation and support in research-intoteaching projects (as described in Phase-1 project reports).

\begin{tabular}{|c|c|c|c|}
\hline Stage & Coordinating & Integrating & Disseminating \\
\hline Main Tasks & $\begin{array}{l}\text { * Define Project Aim } \\
\text { * Select Group } \\
\text { Participants } \\
\text { * Plan Seminar/Research } \\
\text { Format }\end{array}$ & $\begin{array}{l}\text { * Explore Alternate } \\
\text { Disciplinary Understandings } \\
\text { of Project Topic } \\
\text { * Allocate and Coordinate } \\
\text { Sub-Group Research Tasks } \\
\text { * Present and Discuss } \\
\text { Findings with Whole Group }\end{array}$ & $\begin{array}{l}\text { * Enhance Lessons/Courses } \\
\text { with Interdisciplinary } \\
\text { Perspectives \& Information } \\
\text { * Lead Educational Dialogs } \\
\text { with Students/Public about } \\
\text { Project Outcomes } \\
\text { * Feedback from Audience } \\
\text { and Peers }\end{array}$ \\
\hline $\begin{array}{l}\text { Preparation } \\
\text { \& Support } \\
\text { Needed }\end{array}$ & $\begin{array}{l}\text { - Discuss basic } \\
\text { epistemological and } \\
\text { methodological foundations } \\
\text { in each others' fields. } \\
\text { - Know each other's } \\
\text { backgrounds/resources, } \\
\text { explore opportunities for } \\
\text { collaboration. } \\
\text { - Ensure that faculty can } \\
\text { articulate a vision for their } \\
\text { project and agree about } \\
\text { division of labor. } \\
\text { - Hear participant visions of } \\
\text { directions that the group } \\
\text { work might take. } \\
\text { - Select a concrete case-study } \\
\text { to ground the project, before } \\
\text { broadening out to more } \\
\text { global questions. } \\
\text { - Decide how to pair students } \\
\text { across disciplines, to } \\
\text { stimulate discussions and } \\
\text { collaborations. } \\
\text { - Choose required readings as } \\
\text { a starting point for a general } \\
\text { discussions; have a rationale } \\
\text { for ordering presented } \\
\text { materials. }\end{array}$ & $\begin{array}{l}\text { - Assign a discussion facilitator to } \\
\text { highlight key points in readings } \\
\text { and help focus discussions. } \\
\text { - Recognize that age/expertise can } \\
\text { be intimidating: organize small } \\
\text { group discussions and social } \\
\text { gatherings to develop cohort } \\
\text { rapport and embolden question- } \\
\text { asking/answering. } \\
\text { - Help doctoral students to connect } \\
\text { with faculty and other resources } \\
\text { from outside of their fields, } \\
\text { to push them to think } \\
\text { differently about their research, or } \\
\text { approach it with additional tools. } \\
\text { - Focus on delivering a few multi- } \\
\text { disciplinary outcomes: too many } \\
\text { commitments will incline } \\
\text { individuals to stick to their } \\
\text { "expertise" for efficiency. } \\
\text { - Ensure that faculty regularly attend } \\
\text { seminars, both to learn and to give } \\
\text { feedback on students' } \\
\text { research/presentations. } \\
\text { - Encourage research sub-groups to } \\
\text { present work at a stages when they } \\
\text { genuinely need feedback on work- } \\
\text { in-progress. }\end{array}$ & $\begin{array}{l}\text { - Dedicate time to studying } \\
\text { teaching concepts, and covering } \\
\text { basic steps for preparing } \\
\text { presentations and lectures. } \\
\text { - Have faculty work closely with } \\
\text { doctoral students to integrate } \\
\text { their research into their teaching. } \\
\text { - Allow doctoral students a sense } \\
\text { of ownership in developing and } \\
\text { teaching course sections: this } \\
\text { inspires them to think seriously } \\
\text { about presenting effectively to a } \\
\text { larger audience. } \\
\text { - Meet regularly with grads during } \\
\text { their teaching assignments, } \\
\text { maintaining a close relationship } \\
\text { and communication about } \\
\text { classroom experiences. } \\
\text { - Have faculty observe doctoral } \\
\text { students teaching in courses: get } \\
\text { a sense of the types of questions } \\
\text { that students are asking. } \\
\text { - Read student reviews, or talk to } \\
\text { students; get a direct sense what } \\
\text { undergrads are gleaning from } \\
\text { courses. }\end{array}$ \\
\hline
\end{tabular}

Dialog-facilitating activities were then developed to address these needs, based on well-established strategies for promoting active learning in collaborative environments (Webb 2009). These interventions were scheduled cooperatively and flexibly with the input of group leaders into Phase 2 projects (Appendix A: Table II), timed and integrated so as to maximize their benefit to each project's distinct educational and practical goals. After interventions, informal pre/post discussions with lead faculty, continued observations of group meetings, and reflective panel discussions with doctoral students were conducted to determine the impact of these activities on project dialogs, and interventions were refined accordingly. Thus each iteration of facilitation was informed by feedback 
Since participant buy-in was important to the efficacy of facilitation, some activities were done with only one or a few groups (for instance, if a project leader already had a similarly purposed activity for their group in place, we would skip that activity or alter it to complement their activity) while other interventions were welcomed and applied in all or most groups. Examples of those activities are described below.

\section{Results}

The order for introducing dialog-supporting interventions into interdisciplinary projects was somewhat flexible, but groups generally utilized these activities in a sequence like that pictured in Figure 1 . In the coordinating stage, initial activities are facilitated with lead faculty to give them a shared and explicit sense of where the project is going and for what purpose (Appendix B). The next three activities are done with the whole group, moving from setting general project aims to integrating participants' knowledge-bases and approaches via series of defined group tasks (Appendix C). The final four activities are intended specifically for doctoral students or whoever will be teaching people about the group's integrated findings, moving from educating peers within the project to disseminating those shared understandings to target audiences with compelling storylines and relatable language (Appendix D).

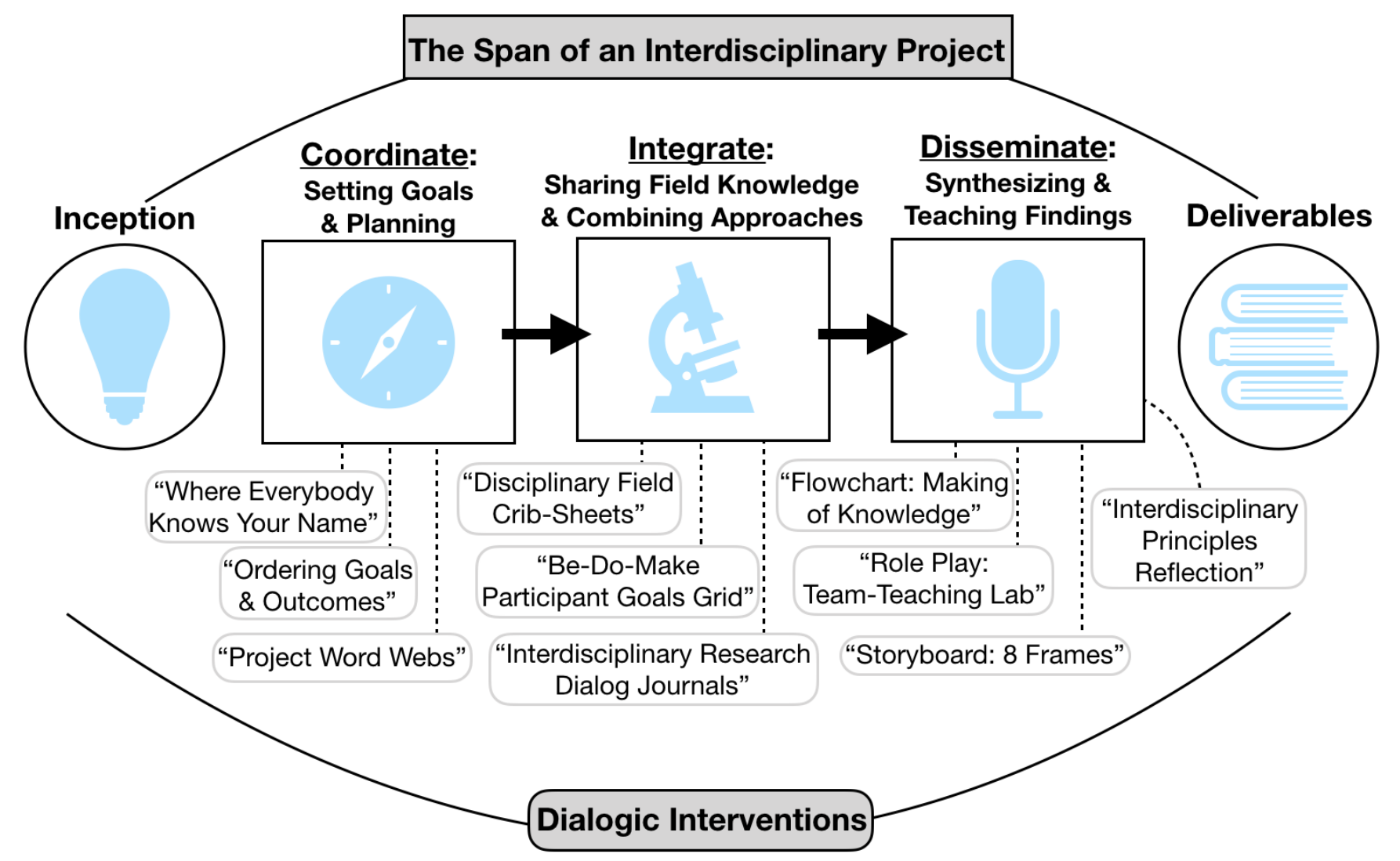

Figure 1: the placement of facilitated dialog activities within the progressive stages of an interdisciplinary research-into-teaching collaboration.

Interdisciplinary groups found the coordination-stage activities useful for bringing forward issues of expertise and background knowledge: affirming their shared interests, naming their disciplinary strengths, and clarifying their differences in practical priorities, so that these positions could be 
negotiated and resolved from the outset. The Green Chemistry (GC) faculty appreciated seeing how many common goals they had for their project's outcomes, then spent time discussing differences in their ordering of those priorities (Appendix B: Activity 2). The "Word Webs" activity allowed the California Grizzly Reintroduction (CGR) group to talk themselves toward similar clarity, finding and resolving unexpected differences in perspective, e.g., between political scientists and ecologists, as they negotiated arranging key words into a shared visual map of their project (Appendix B: Activity 3).

The integration-stage activities were used in various ways by project groups, sometimes as a multi-day exploration and other times as a conceptual backdrop for a timely conversation. Yet these activities served a distinct role in the projects: helping individuals to understand other disciplines' relevant threshold concepts, to ask pointed questions to stimulate the group's social learning processes, and to voice personal motives as decisions were made about translating group goals in practical tasks. The "Crib Sheet" activity, for example, helped Visualizing Environmental Models (VEM) participants launch hours-long conversations about the core terminology and methods that distinguished their disciplines (Appendix C: Activity 4). Relatedly, the "Be-Do-Produce" grid helped the GC project's faculty and graduate fellows in mapping out together the core structure of their educational presentation series for chemistry students (Appendix C: Activity 5; Figure 2 below).

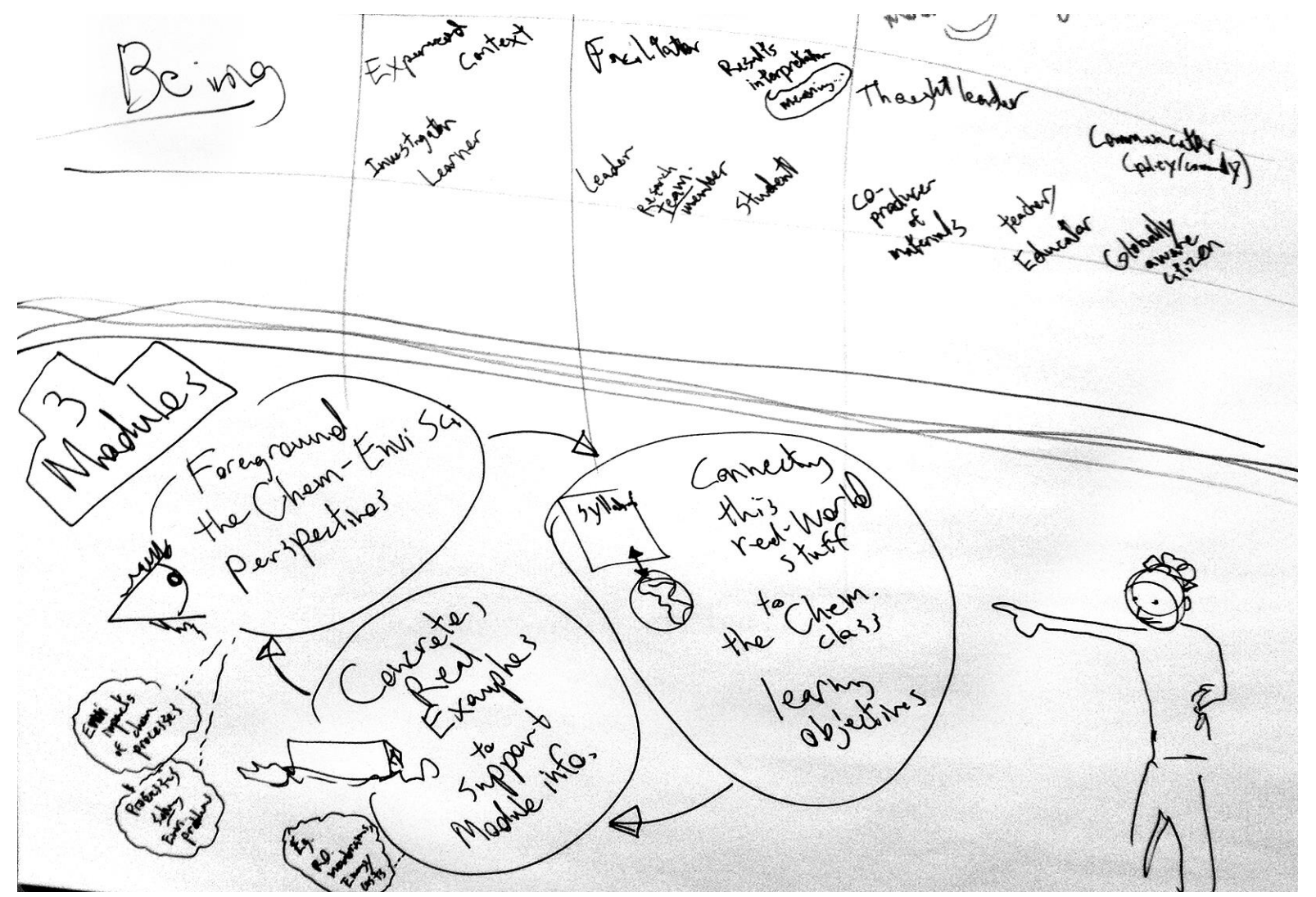

Figure 2: Green Chemistry Project, group brainstorm plan for a series of educational modules, using ideas discussed in their "Be-Do-Produce" activity.

The dissemination-stage activities then helped doctoral students to reflect more consciously on how they build knowledge in their disciplines, how they can explain the need for interdisciplinary collaboration to students/novices/the public, and how they can summarize their complex research succinctly without getting lost in the details. The VEM students took initiative to do "Making of Knowledge" flowcharts about their own research, rather than their field in general (Appendix D: 
Activity 7). This closer-to-home version of the activity stimulated such a detailed conversation about their field's complementary strengths and weaknesses that we repeated that variant for the Spatial Navigation (SN) and Unconscious Mind (UM) groups as well. The GC and UM groups both engaged enthusiastically in the Team-Teaching Lab activity (Appendix D: Activity 8), which allowed them to explore strategies for answering novices' questions respectfully and succinctly, one quarter before their Chemistry course presentations. The UM project's lead faculty also specifically requested an activity to prepare their fellows for upcoming conference presentations, which lead to the creation of the "Eight Frames" storyboard activity (Appendix D: Activity 9). This creative exercise pressed them to explain the importance of their research topics in a single sentence and illustrate that work coherently in a series of images, testing their narrative clarity and focus - the fellows expressed particular appreciation for this activity:

Once again, we see how written language is completely different from spoken language. [A conference paper] has to be focused on a few ideas that are discussed with repetition for retention and with proper transitions to allow the paper to unfold in the mind of the audience. The connections between concepts must be clear and purposeful and doing the storyboarding showed me that this was one of my weak points.

The final meta-reflection about "Interdisciplinary Principles" directed doctoral students to distill their dialog journals from the previous months (Appendix C: Activity 6) into a list of insights they've gained about productive interdisciplinary collaboration. The UM group was the first to explicitly emphasize "tolerance of ambiguity" as a principle. Yet most groups reliably mentioned some version of "establishing a shared project language" and "establishing interpersonal rapport" as important, so that members can productively challenge and sustainably support one another in co-creating scholarly work (see journal samples in Appendix D: Activity 10).

Project leaders had varying levels of experience with interdisciplinary collaboration, and the groups most familiar with the difficulties of collaboration processes were also most enthusiastic about having structured interventions. Predictably, groups that proactively integrated the dialog activities to fortify their existing project development (e.g., the VEM and GC projects) reported most benefit from those interventions. In groups that opted out of certain activities, either because they had their own versions (e.g., UM) or did not recognize a pressing need for interventions (e.g., SN), doctoral students and faculty reported either minor or major communication-based issues that interventions were meant to address - ranging from missed opportunities to request skills or methods training to extended confusion about group time management and independent task expectations.

This feedback generally validated the utility of offering targeted dialog-facilitation activities to support interdisciplinary groups' research and teaching collaborations. Moreover, implementing these activities with cycles of feedback and adjustment helped Crossroads to refine the manner and timing of its interventions within the dynamic stages of interdisciplinary work. Specifically, these trial interventions helped Crossroads to understand where participants perceive interventions will fit best in their projects (i.e., maximizing group receptivity or "buy-in" with facilitations), why experienced groups appreciate interventions (i.e., persuasively expressing the purpose of activities), and which details of facilitation make an intervention work (i.e., scaffolding dialogs so that participants understand what they're doing in these confusion-evoking exchanges).

\section{Discussion}

The challenges of interdisciplinary collaboration are well-known: coordinating language, integrating 
approaches, and maintaining open communication in the face of intellectual and interpersonal differences. Less commonly emphasized in practice is that making participants notionally "aware" of these issues is not enough; the path to overcoming these challenges inevitably centers on constructive, intentional, fully involved group dialogs. Participants involved in such demanding work need structured support — and sometimes active persuasion — to progress through these often surprisingly tricky stages of collaborative development.

The Crossroads program has developed a methodology for doing this. Broadly speaking, facilitating interdisciplinary dialogs begins by creating activities that require participants to explicitly define and carefully organize ideas: key terms, simple examples, and operational connections. The next step requires weaving these activities into the existing flow of a project: discussing with leaders what they are doing, what activities might help that process, and how they might utilize the outcomes/artifacts of those interventions. The final step is paring down, enriching, or altering these activities as needed to complement the rest of that group's work: limiting redundancy, emphasizing utility, and prioritizing appropriateness over consistency in practice.

The outcome of this methodical process, for Crossroads, has been a series of effectively refined group activities. The active dialog-centered approach and responsively iterative method for refining these activities provides a useful model to other programs for supporting academic collaborations. Of course, programs with alternative structures, in other institutions, or with distinct goals may benefit from different types of activities. 


\section{Works Cited}

Begg, M. D., \& Vaughan, R. D. (2011). Are biostatistics students prepared to succeed in the era of interdisciplinary science?(And how will we know?). The American Statistician, 65(2), 71-79.

Boden, D., Borrego, M., \& Newswander, L. K. (2011). Student socialization in interdisciplinary doctoral education. Higher Education, 62(6), 741-755.

Boix Mansilla, V., Lamont, M., \& Sato, K. (2016). Shared cognitive-emotional-interactional platforms: markers and conditions for successful interdisciplinary collaborations. Science, Technology, \& Human Values, 41(4), 571-612.

Chen, S., Arsenault, C., \& Lariviere, V. (2015). Are top-cited papers more interdisciplinary?. Journal of Informetrics, 9(4), 1034-1046.

Derrick, E. G., Falk-Krzesinski, H. J., Roberts, M. R., \& Olson, S. (2011). Facilitating interdisciplinary research and education: A practical guide. Boulder, CO: American Association for the Advancement of Science.

Donovan, S. M., O’Rourke, M., \& Looney, C. (2015). Your hypothesis or mine? Terminological and conceptual variation across disciplines. Sage Open, 5(2), 2158244015586237.

Eigenbrode, S. D., O'rourke, M., Wulfhorst, J. D., Althoff, D. M., Goldberg, C. S., Merrill, K., ... \& Bosque-Pérez, N. A. (2007). Employing philosophical dialogue in collaborative science. AIBS Bulletin, 57(1), 55-64.

Felt, U., Igelsböck, J., Schikowitz, A., \& Völker, T. (2013). Growing into what? The (un-) disciplined socialisation of early stage researchers in transdisciplinary research. Higher education, 65(4), 511-524.

Fisher, E., O'Rourke, M., Evans, R., Kennedy, E. B., Gorman, M. E., \& Seager, T. P. (2015). Mapping the integrative field: Taking stock of socio-technical collaborations. Journal of Responsible Innovation, 2(1), 39-61.

Gamse, B. C., Espinosa, L. L., \& Roy, R. (2013). Essential Competencies for Interdisciplinary Graduate Training in IGERT: Final Report. GS-10F-0086K. Abt Associates.

Gilkey, M. B., \& Earp, J. A. L. (2006). Effective interdisciplinary training: lessons from the University of North Carolina's student health action coalition. Academic Medicine, 81(8), 749-758.

Graybill, J. K., Dooling, S., Shandas, V., Withey, J., Greve, A., \& Simon, G. L. (2006). A rough guide to interdisciplinarity: Graduate student perspectives. AIBS Bulletin, 56(9), 757-763.

Hmelo-Silver, C. E., \& Barrows, H. S. (2006). Goals and strategies of a problem-based learning facilitator. Interdisciplinary journal of problem-based learning, 1(1), 4.

Kahneman, D., \& Klein, G. (2009). Conditions for intuitive expertise: A failure to disagree. American Psychologist, 64(6), pp. 515-526

Kaner, S. (2014). Facilitator's guide to participatory decision-making. John Wiley \& Sons. 
Meyer, J., \& Land, R. (2006). Overcoming barriers to student understanding: Threshold concepts and troublesome knowledge. Routledge.

National Academies of Sciences, Engineering, and Medicine. (2018). The Integration of the Humanities and Arts with Sciences, Engineering, and Medicine in Higher Education: Branches from the Same Tree. National Academies Press.

Nielsen-Pincus, M., Morse, W. C., Force, J. E., \& Wulfhorst, J. D. (2007). Bridges and barriers to developing and conducting interdisciplinary graduate-student team research. Ecology \& Society.

Royse, D., Staton-Tindall, M., Badger, K., \& Webster, J. M. (2009). Needs assessment (Vol. 8). OUP USA.

Tuomi-Grohn, T., Engestrom, Y., \& Young, M. (2003). From transfer to boundary-crossing between school and work as a tool for developing vocational education: An introduction. Between school and work: New perspectives on transfer and boundary-crossing, 1-15

Turner, V. K., Benessaiah, K., Warren, S., \& Iwaniec, D. (2015). Essential tensions in interdisciplinary scholarship: navigating challenges in affect, epistemologies, and structure in environment-society research centers. Higher Education, 70(4), 649-665.

Webb, N. M. (2009). The teacher's role in promoting collaborative dialogue in the classroom. British Journal of Educational Psychology, 79(1), 1-28.

Welch-Devine, M., Hardy, D., Brosius, J. P., \& Heynen, N. (2014). A pedagogical model for integrative training in conservation and sustainability. Ecology and Society, 19(2).

*

This material is based upon work supported by the National Science Foundation under Grant No. 1633764

For questions or further information about the following project dialog activities and their facilitation in interdisciplinary projects, contact Josh Kuntzman.

kuntzman@ucsb.edu 


\section{Appendix A: Crossroads Interdisciplinary Projects}

Table I: Crossroads Program - Phase 1. Interdisciplinary groups, aims, and disciplines involved.

\begin{tabular}{|l|l|l|}
\hline \multicolumn{1}{|c|}{ Group } & \multicolumn{1}{|c|}{ Aim } & \multicolumn{1}{c|}{ Disciplines Involved } \\
\hline $\begin{array}{l}\text { SKILLS } \\
\text { School Kids } \\
\text { Investigating Language }\end{array}$ & $\begin{array}{l}\text { Investigating the politics of race and language in } \\
\text { learning contexts }\end{array}$ & $\begin{array}{l}\text { Linguistics, Education, } \\
\text { Chicanx Studies }\end{array}$ \\
\hline $\begin{array}{l}\text { PEPP } \\
\text { (Psychology, } \\
\text { Environment, and Public } \\
\text { Policy) }\end{array}$ & $\begin{array}{l}\text { Exploring how presentation of environmental } \\
\text { politics and policy influences individual and } \\
\text { collective reactions }\end{array}$ & $\begin{array}{l}\text { Psychology\& Brain } \\
\text { Sciences, Environmental } \\
\text { Science \& Management }\end{array}$ \\
\hline $\begin{array}{l}\text { Climate Justice } \\
\text { Futures }\end{array}$ & $\begin{array}{l}\text { Examining movement, gender, and media related to } \\
\text { the issue of climate change }\end{array}$ & $\begin{array}{l}\text { Sociology, Film \& Media } \\
\text { Studies, Feminist Studies, } \\
\text { English }\end{array}$ \\
\hline $\begin{array}{l}\text { M3 } \\
\text { (Materials, Mechanics, } \\
\text { and Medicine) }\end{array}$ & $\begin{array}{l}\text { Studying how chrondrocytic cell differentiation is } \\
\text { controlled by mechanical cues in cellular } \\
\text { aggregates }\end{array}$ & $\begin{array}{l}\text { Chemical Engineering, } \\
\text { Mechanical Engineering, } \\
\text { Neuroscience }\end{array}$ \\
\hline $\begin{array}{l}\text { REM } \\
\text { (Religion, Experience, } \\
\text { and Mind) }\end{array}$ & $\begin{array}{l}\text { Using concepts from cognitive science and } \\
\text { evolutionary psychology to inform explanations of } \\
\text { spiritual and religious phenomena }\end{array}$ & $\begin{array}{l}\text { Religious Studies, } \\
\text { Psychological \& Brain } \\
\text { Sciences }\end{array}$ \\
\hline Borderlands & $\begin{array}{l}\text { Examining how people get along, or fail to get } \\
\text { along, in the absence of a strong state (e.g., in the } \\
\text { southwest borderlands of North America) }\end{array}$ & History, Anthropology \\
\hline
\end{tabular}


Table II: Crossroads Program - Phase 2. interdisciplinary groups, aims, and involved disciplines.

\begin{tabular}{|l|l|l|}
\hline \multicolumn{1}{|c|}{ Group } & \multicolumn{1}{|c|}{ Aim } & \multicolumn{1}{c|}{ Disciplines Involved } \\
\hline $\begin{array}{l}\text { CGR } \\
\text { Reintroduction) }\end{array}$ & $\begin{array}{l}\text { Studying the biological, ecological, social, political, } \\
\text { and historical factors relevant when considering } \\
\text { strategies for reintroducing grizzly bears to } \\
\text { California after a 100-year absence. }\end{array}$ & $\begin{array}{l}\text { Ecology, History, Political } \\
\text { Science, Education }\end{array}$ \\
\hline $\begin{array}{l}\text { GC } \\
\text { (Green Chemistry) }\end{array}$ & $\begin{array}{l}\text { Analyzing the physical/chemical processes } \\
\text { involved in materials-recycling and the broader } \\
\text { environmental costs/benefits of those processes. }\end{array}$ & $\begin{array}{l}\text { Chemistry, Chemical } \\
\text { Engineering, } \\
\text { Environmental Science \& } \\
\text { Management }\end{array}$ \\
\hline $\begin{array}{l}\text { VEM } \\
\text { (Visualizing }\end{array}$ & $\begin{array}{l}\text { Exploring ways to make visualizations of } \\
\text { environmental data more transparent, } \\
\text { comprehensible, interactive, and efficient. }\end{array}$ & $\begin{array}{l}\text { Environmental Science \& } \\
\text { Management, Human- } \\
\text { Computer Interaction, } \\
\text { Statistics \& Probability }\end{array}$ \\
\hline $\begin{array}{l}\text { UM } \\
\text { (Unconscious Mind) }\end{array}$ & $\begin{array}{l}\text { Defining the nature and significance of } \\
\text { unconscious memory, integrating relevant research } \\
\text { on human memory, artificial intelligence and } \\
\text { literary elaborations on the unconscious. }\end{array}$ & $\begin{array}{l}\text { English, Neuroscience, } \\
\text { Computer Science }\end{array}$ \\
\hline $\begin{array}{l}\text { SN } \\
\text { (Sex Differences in } \\
\text { Spatial Navigation) }\end{array}$ & $\begin{array}{l}\text { Examining the relationship between sex hormones, } \\
\text { spatial navigation, and aging, integrating research } \\
\text { on sex differences, evolution of spatial cognition, } \\
\text { brain and behavior, neuroscience and aging. }\end{array}$ & $\begin{array}{l}\text { Psychological \& Brain } \\
\text { Sciences, Geography, } \\
\text { Anthropology }\end{array}$ \\
\hline
\end{tabular}




\section{Appendix B: Interdisciplinary Dialog-Facilitating Activities}

\section{Coordinating Stage}

\section{Activity 1.}

"Where Everybody Knows Your Name"

Prompts for Introducing Participants.

Activity 2.

"Ordering Goals and Outcomes"

Lists for Sorting Priorities of a Project.

Activity 3.

"Project Word Webs"

Map for Visualizing Group Purpose. 
Activity 1. "Where Everybody Knows Your Name" Prompts for Introducing Participants.

Description: A semi-structured discussion to help new interdisciplinary project leaders talk explicitly about their interests, skill-sets, and hopes as that project begins.

WHEN: Before the project gets underway, just the group leaders together.

WHY: Gives leadership a fundamental sense of each other's various views and drives in the project. HOW: Semi-structured faculty discussion, moderated by Project Coordinator or other Facilitator.

\section{STEP 1. The Cards.}

Sit around a table. Give each participant in the discussion one [Note-Card] to fill out for themselves: their Name / Department at the top, and underneath: "I Value...," "Goals," and "Skills."

\begin{tabular}{|l|}
\hline "I Value..." \\
\hline Goals: \\
\hline Skills: \\
\hline
\end{tabular}

Make clear to participants that these are not necessarily project-specific values, goals, or skills-rather they will be focusing on individuals' broader disciplinary perspectives, drives, and abilities (setting up an informed interpersonal foundation for the collaborative project negotiations to come).

Once they have filled their card out, they can turn it around for others at the table to view, read others' cards, and use [Paper and Pen] to make notes about each person (noteworthy facts, any questions, etc.).

\section{STEP 2. The Introductions.}

Once everyone has read the front of each others' cards, have all participants turn over their cards and on the BACK, fill in two [Introductory Sentence Frames] (e.g., samples below—or modify to fit your group), one about themselves and one about their conception of the group:

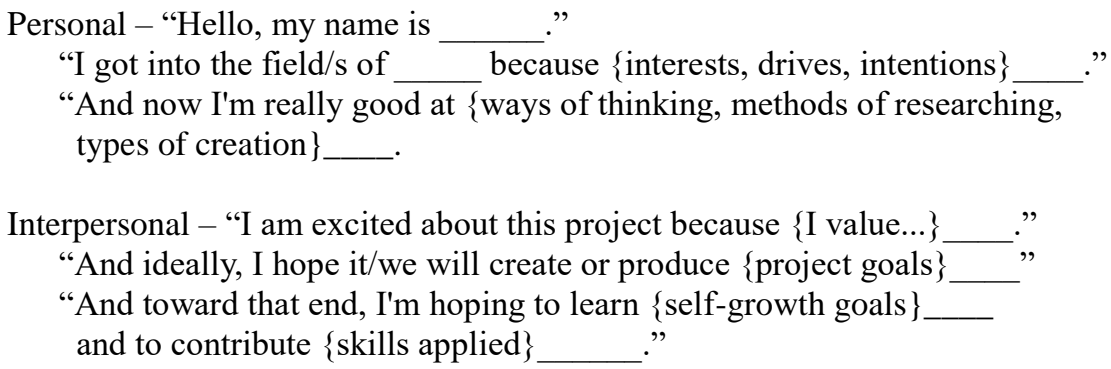

Have participants take turns introducing themselves based on what they write down. Remind everyone else to take notes on each person using the speaker's words ("their personal dictionary; not your own") and mark with an asterisk (*) if you're not certain what they mean by a word - to prep for follow-up.

\section{STEP 3. The Discussion.}

Have participants use their notes to discuss terms they're not sure about, person by person ...

"What did you mean by this skill? This goal? This overarching value?"

"What / Where" (situate it) - "When / How" (operationalize it) - "Why" (make sense of it)

... in language that is emotionally open, rationally clear, and motivationally explicit.

$$
\begin{aligned}
& \text { "... that definition / explanation makes me feel } \\
& \text { and I think that's because } \\
& \text { And personally, I'd really like to } \\
& \text { How's that sound? ", }
\end{aligned}
$$

PS: The Sell - If group leaders are hesitant to set aside time for this activity, ask them: (1) Do they they know the backgrounds of their fellow leaders, well enough to introduce them to the rest of the project's participants? (2) Do they know the interests and skill-sets of these peers relative to the project, well enough to anticipate their priorities and concerns, as well as tools they bring to help with those issues, as the project progresses? THIS is the goal of these structured intros. 


\section{$\underline{\text { INTRODUCTIONS }}$}

Personal -

"Hello, my name is

9

"I got into the field/s of

because

\{interests, drives, intentions \}."

"And now I'm really good at

\{skills: thinking how, researching what, creating what?\}.

\section{Interpersonal -}

"I am excited about this project because

\{I value....."

"And ideally, I hope it/we will create or produce

\{project goals\}"

"And toward that end, I'm hoping to learn

\{self-growth goals\}

and to contribute

\{skills applied\}." 


\section{ANY QUESTIONS?}

... in language that is emotionally open, rationally clear, and motivationally explicit.

\section{Basic Understandings:}

"What did you mean by this Skill, Goal, or overarching Value?"

$\sim$ What / Where (situate) - When / How (operationalize) - Why (make sense of)

\section{Honest Responses:}

"... that definition / explanation makes me feel and I think that's because

And personally, I'd really like to How's that sound?" 


\section{Activity 2. "Ordering Goals and Outcomes" Lists for Sorting Priorities of a Project.}

Description: A listing-and-sharing activity to help leaders define core research and educational interests of a project, and the concrete outcomes they hope to achieve, as a precursor for planning that project's structure and timeline.

WHEN: Within the first two weeks of the project, just the leaders together.

WHY: To coordinate ideas and language, in defining the priorities of the project.

(Also prepares leaders to facilitate whole-group dialog-coordinating activities that follow)

HOW: Negotiating the project's central topic-terms and intended outcomes (primary and potential).

\section{STEP 1. List-Making. List-Prioritizing.}

Give each leader a [Half-sheet of Paper], that they can tear into strips (e.g., below) or sticky-notes, etc. and [Two Pens - one Black, one Blue]. Also give them a [Two-Columned Sheet of Paper], with columns labeled "Project Focus" and "Project Outcomes."

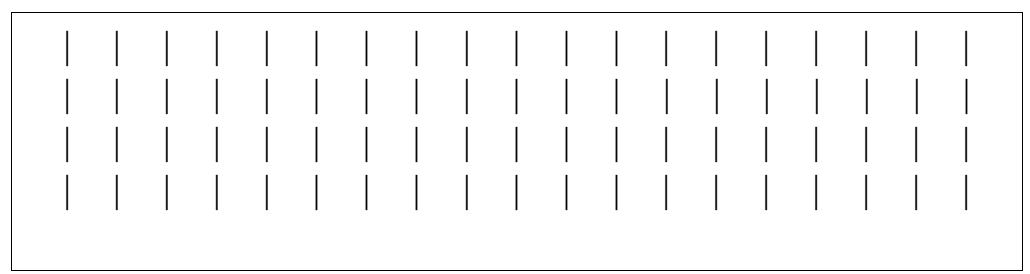

Have them begin by listing important topics, terms, and/or phrases related to the project (black ink) on strips of paper and placing them in column one; potentially desirable outcomes for the project (blue ink) in column two. Encourage them to write freely, as topics and products come to mind, in no order; anywhere between 10 and 20 items per list.

Next, have them sort these strips in each column, in order of importance. Which do they see as the most ESSENTIAL TOPIC-TERMS and most realistic/valuable POTENTIAL CONCRETE OUTCOMES.

\section{STEP 2. List-Comparing. List-Negotiating.}

Now, let the leaders compare their lists. Underline those terms which show up in multiple individuals' lists; asterisk * those terms which come in high on everybody's list.

Discuss these common/valued topics to make sure everyone roughly agrees on the meaning of these essential terms (or at least understands and accepts variations among each others terms). Do likewise with the outcomes, to make sure people roughly agree on the practical form of these outcomes (i.e., end products and related processes).

If there are any terms or outcomes that only one individual has included, but places high on their list, take time to discuss these items for possible inclusion. Combine/distill the lists down on one [Shared "Focus/Outcomes" sheet].

\section{STEP 3. List-Connecting.}

Are certain ideas linked to certain outcomes? Do certain terms precede others, in the timeline of this project, or subsume others, like an abstract notion that helps organize multiple concrete details?

Beginning with these questions, let group leaders talk out the interrelation of their terms and COMBINE their lists on one [Map Page], where topics and outcomes are ordered into a practical flow.

Remember to start with the pieces most important to you:

Top-priority topics $\rightarrow$ related outcomes.

Mid-priority topics $\rightarrow$ related outcomes.

Other important topics $\rightarrow$ possible additional outcomes. 


\section{"WHAT WE'RE REALLY TALKING ABOUT" ACTIVITY STEPS:}

List - Take two pens.

Write down Important topic-terms (the project's focus - in BLACK)

$\&$ Desirable results (the project's outcomes - in BLUE).

Organize - Tear these items off into separate pieces, and sort them as two columns, in order of importance (to you).

Compare - Look at each other's lists. Then, on your own list, ... Underline those items which show up on multiple peoples' lists. Asterisk $*_{-}^{*}$ those items which are rated high on multiple peoples' list.

\section{Discuss / Connect - Discuss these commonly agreed and / or ${ }_{-}^{-}$highly-valued terms.}

** Does everyone agree — or understand variations in perspective — on the meaning of these essential terms?

Do likewise with the outcomes.

** Do people roughly agree on the practical form that these results will take?

If there are any terms or outcomes that only one individual has included, but places high on their list, take time to discuss these items for possible inclusion.

Combine / distill the lists down on one shared "Focus / Outcomes" sheet.

Organize - Talk about the practical interrelation of these terms and outcomes.

Think about how to map these topics + outcomes into an operational flow (or refine your existing plans). 


\section{PROJECT FOCUS}

$\sim$ (important topic-terms)

\section{PROJECT OUTCOMES}

$\sim$ (potential, desirable, concrete results) 


\section{A MAP:}

(Do certain topics link to specific outcomes? Do certain terms precede others, in the timeline of this project, or subsume others, as guiding ideas might connect multiple concrete details? ... map your priorities into a practical flow.)

initially

finally

$-$

$-$ 


\section{Example Goals \& Outcomes: Green Chemistry}

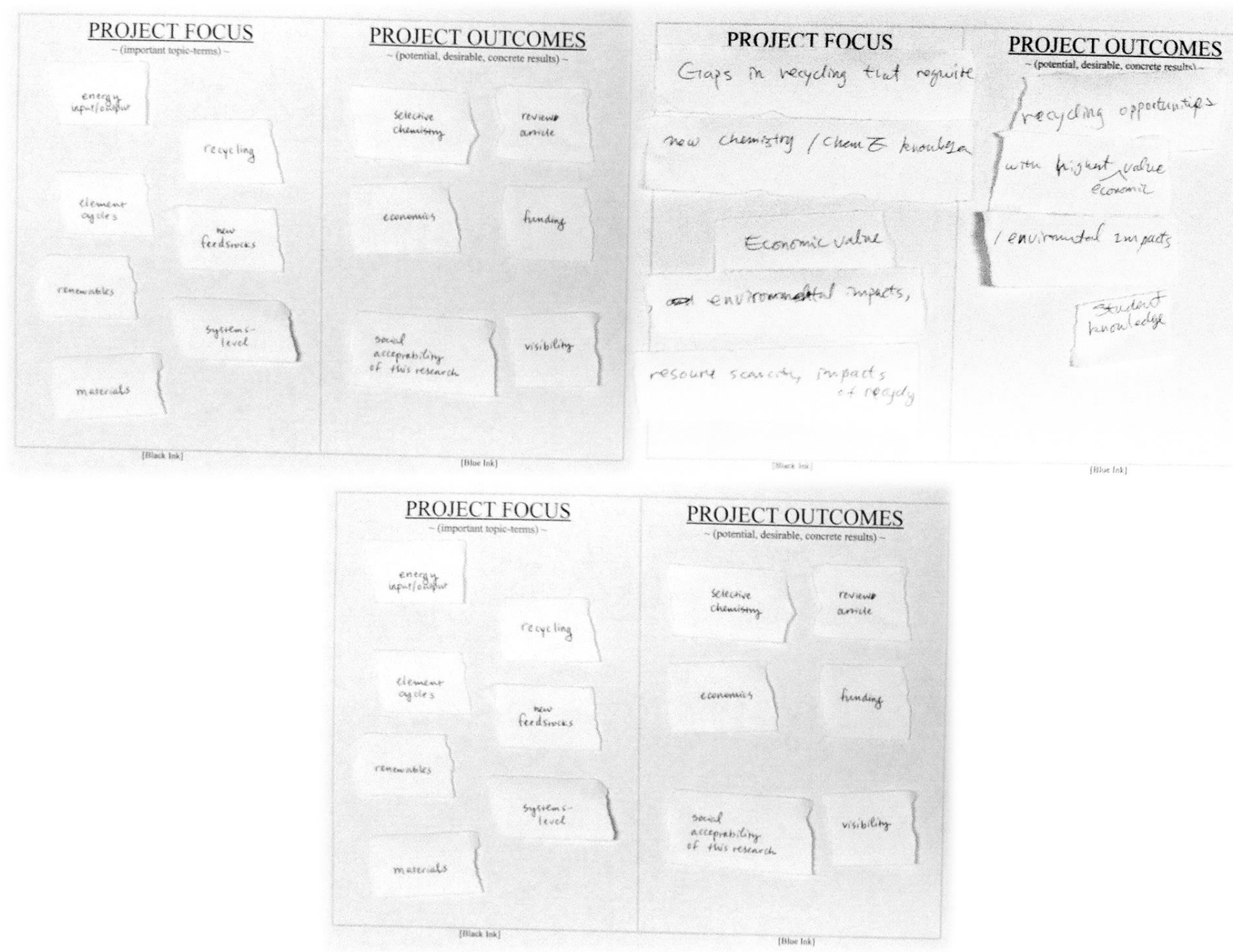




\section{Activity 3. "Project Word Webs" Map for Visualizing Group Purpose.}

Description: A key-terms mapping exercise to help groups discuss the central focus of their project and create a visual representation of that conceptual/topical space together.

WHEN: As the whole-group project begins, leaders and all participants (e.g., faculty/students) together. WHY: To give all group members a coordinated sense of the project's focus and purpose: "Making sure we know what each other means."

HOW: Note-card and Sticky-note word mapping activity (to create a manipulable image of the project's essential parts, that can be easily moved and altered as the group negotiates what is central, what comes first, what finally emerges, etc.)

\section{STEP 1. Important Words - in Common Language.}

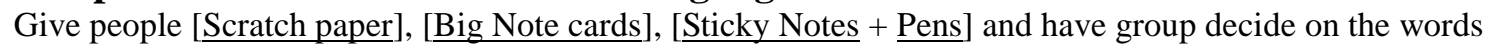
(terms, phrases) most essential for this project, in two steps:

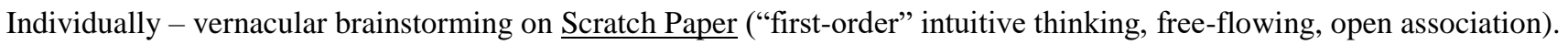

*ALLOW: words of actions, situations, objects, ideas, feelings - in vernacular, conversational language.

Groups of 3-8 - Compare and distill words onto notes ("second-order" critical thinking, prioritizing, combine where able). *ALLOW: hierarchal sorting ("Which words encapsulate several others?"), type sorting ("Is this a Big Idea or a Concrete Detail?"), connecting ("To which subject/s is this adjective relevant?"), replacing ("These are really saying the same thing, and this one is more explicit"), recognizing pragmatic boundaries ("Important idea in general, but not really a project-specific term...").

* Once words are decided, put BIG key terms on Note Cards. Put SUPPORTING details on Sticky Notes.

\section{STEP 2. Word Connections - See the Project's Shape.}

Bring all the groups' words together; build and arrange them into an image that represents the project, on a [Floor or Large Board] ("crowdsourced" synthetic thinking, organizing, discussing).

* START WITH: the big pieces, on Note Cards. Negotiate what \{place/subject/topic $\}$ goes at the center, what \{ideas/values/perspectives $\}$ sit at the top, what $\{$ methods/situations/stakeholders $\}$ come into play beneath that, which \{actions/steps/hurdles come at the front, and which \{short-to-long outcomes/audiences/changes hopefully follow by the end.

*THEN ADD: the details, on Sticky Notes. You can further cut redundant-or-tangential terms as you discuss and adjust this web's main structure.

\section{STEP 3. Draw Lines \& Arrows - See the Project's Flow.}

Once the Word-Clumps are arranged in a way that everyone agrees makes sense, use [Board Markers or Floor Strings, etc.] to visually mark How these parts of the project work together. Now you have a WordWeb.

* If you have any FREE-FLOATING TERMS? See whether they fit between clumps, helping to make connections.

* Insert arrows (where flow is directional: "This leads to that") or double-sided arrows ("This could flow either way") or cycling arrows ("These mutually influence each other") or static lines ("These exist separately but relatedly, regardless of time or consequence").

* If you have any discipline-specific JARGON that you'd reeally like to include? ... Okay, NOW you can add it to the web, without creating major ambiguities in meaning.

\section{Afterward.}

Discuss meanings in context!

*ALLOW: multiple definitions, questions, prompts for explanation/description. Use phrases like these:

"Are you saying __?" "What does__ look like?" "Is __ an example of __? "How does__ differ from __?"




\section{ACTIVITY STEPS: "Word-Webs"}

(Solo) Vernacular Brainstorming - Think about words/terms that are central to this project. Write them down. Notice which words are "Big" words (broad topics, general ideas: e.g., 'data,' 'model,' 'audience') and which are "Small" words that point to details within those larger themes (e.g., 'optimal parameters,' 'color-scheme,' 'store managers'). ( 5 minutes)

* Options: you can assign this as a Take-Home Activity, or you can do it In-Class before breaking into groups.

* Clarifying: if participants need clear directions about what these words should be, offer a prompt to guide them, such as:

"Write out a list of words that you see as essential to this class/project's topic: ideas, things, processes, important

choices/details, etc. that are central to the issue being addressed. Keep the language simple and conversational: single words

or phrases that we can then organize as a group into an image of the group's core focus."

* Use Conversational language. Where specialized terms are important/*unavoidable*, put a plain-language term underneath in parentheses: e.g., "Vernacular (conversational)".

\section{(Group) Compare/Connect Words - Let's get into groups and share our words. Decide which} words are big ideas, truly central to the project (in everyone's eyes), and which are smaller details (that individuals see as important details related to those terms, or filling a gap/making a connection between them). Write the "Big" terms on notecards, and the "small" importantdetail terms on sticky-notes. Attach small-stickies to big-cards, where the group sees a clear connection. It's fine to leave other terms floating ... they'll find a home in the next step. ( 15-20 min.)

* Priming: Keep dialogs focused. (At 5 min.) "Remember: Conversational language, no jargon - if you need it, explain simply in parentheses underneath. And think modularly: basic terms and phrases - that build into something more complex."

(At 15 min.) "Finish getting your ideas down and connected, and start bringing those parts up to the center of the room."

* Numbers: groups of 3-8 people work well. If it's a small class, let the whole group do this together.

If more than 10 people, split the class into medium groups, with people from similar disciplines together.

\section{(Group) Build/Arrange Word-Web - Let's all gather in circle around these terms. Look at and} compare each others' terms. Then start arranging them: what terms are at the core of this project? What informs those central terms (from above), or supports them (from below)? What feeds into them or precedes them (before)? Where are they directed, toward what purpose or eventual impact (after)? Arrange accordingly :) Remove redundant terms. Give everybody's hands access to try at moving things.
“Are you saying
?" "What does
look like?" "Is
an example of
?" "How does differ from 



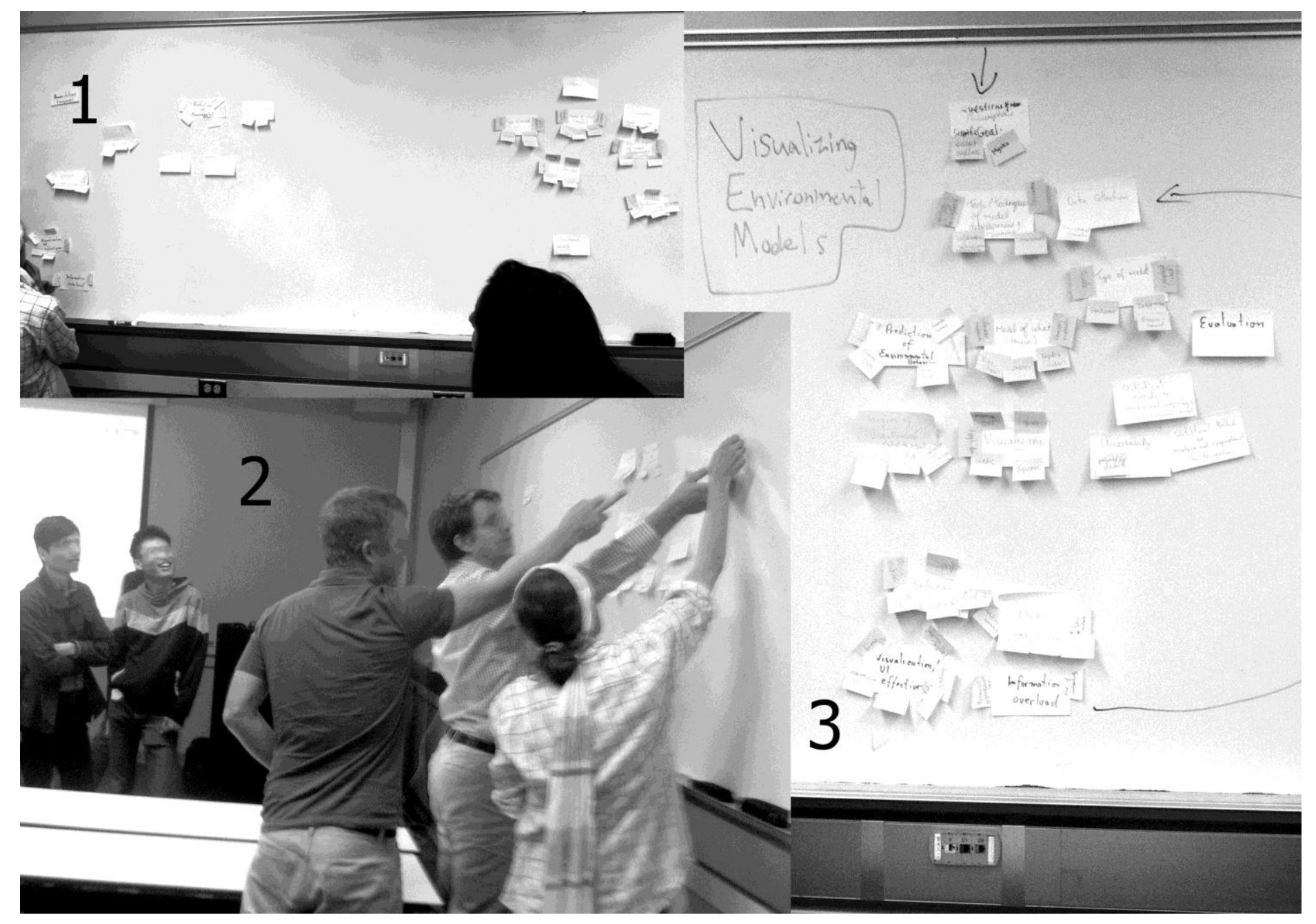

Word-Web Process: Visualizing Environmental Models 


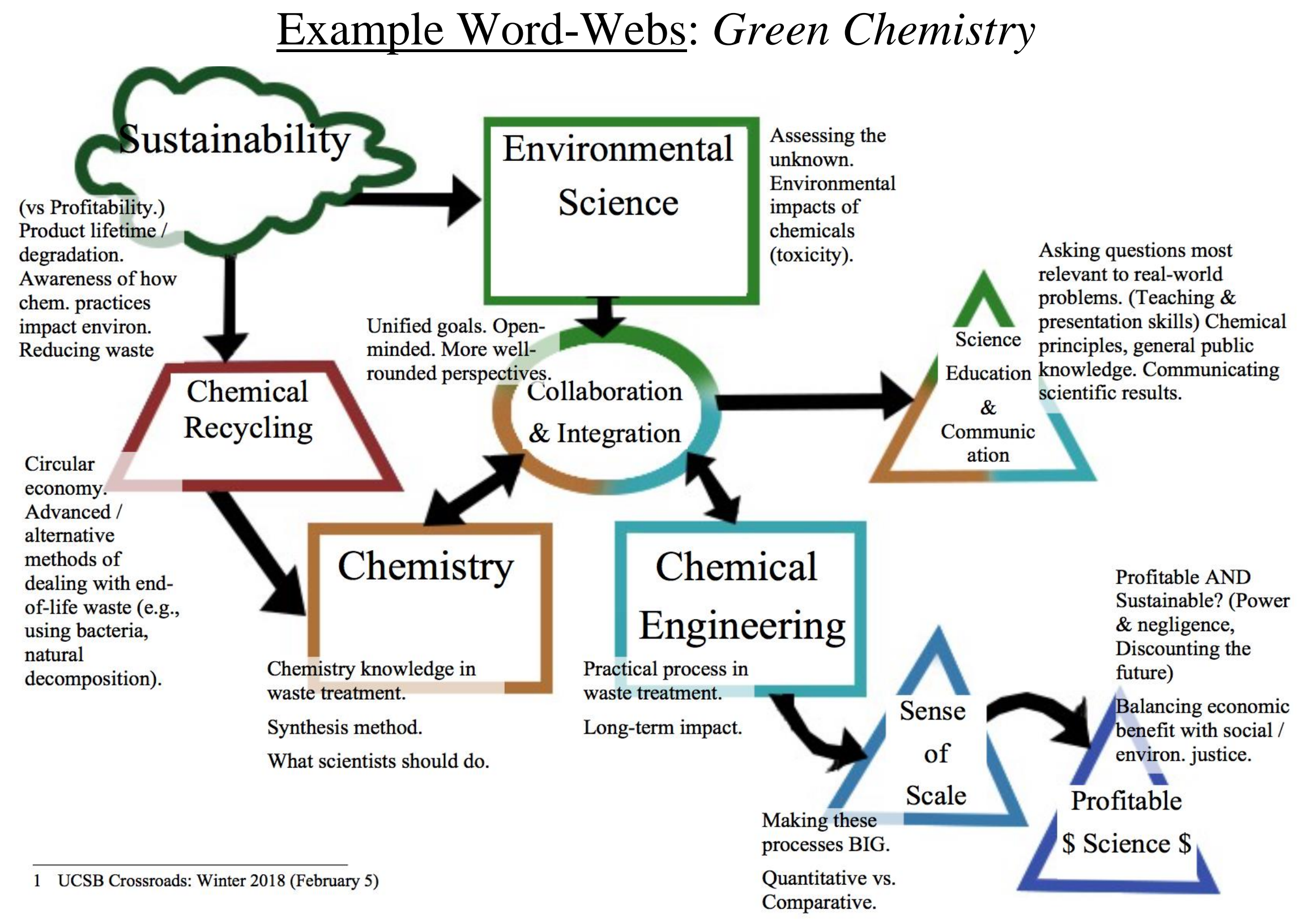


Example Word-Webs: Grizzly Reintroduction Project

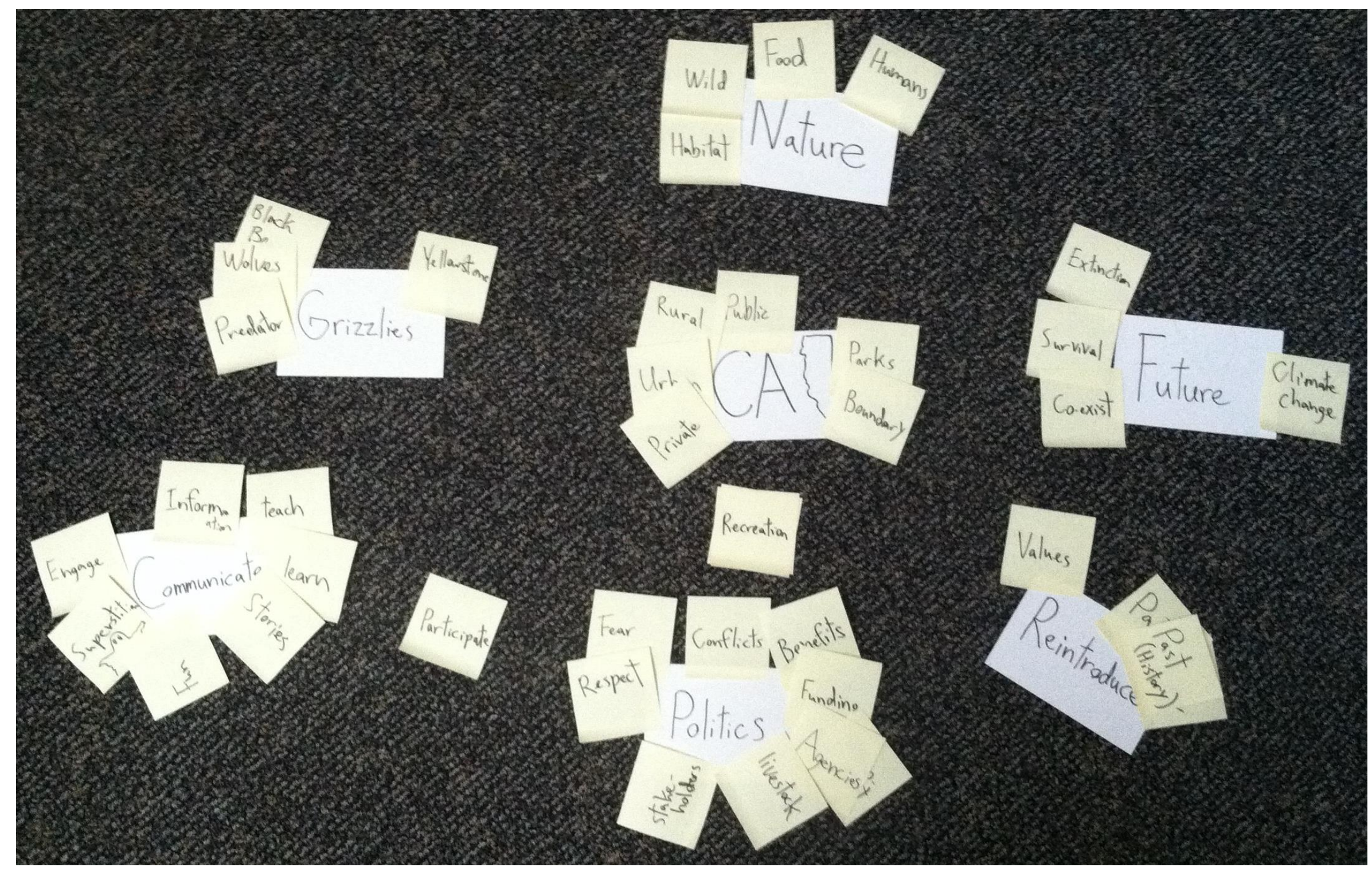




\section{Appendix C: Interdisciplinary Dialog-Facilitating Activities \\ Integrating Stage}

Activity 4.

"Disciplinary Field Crib-Sheets"

Flowcharts for Understanding Disciplines.

Activity 5.

"Be-Do-Make"

Grid of Participants' Goals (and Products).

Activity 6.

"Dialog Journal"

Reflections on Interdisciplinary Research. 


\section{Activity 4. "Disciplinary Field Crib-Sheets" Flowcharts for Understanding Disciplines.}

Description: A show-and-tell activity, operationally linking key pieces of disciplinary jargon, core concepts, methods/data to help interdisciplinary groups discuss the specialized reasons and logic underlying each fields' approaches.

WHEN: Within the first two weeks of the project, all group participants together.

WHY: To learn as a group the core concepts, methods, and relevant vocabulary of all disciplines involved in the project. (Also prepares participants to teach others outside the group.)

HOW: Creating modular overviews of disciplines that show (concisely) the thread from evidence and reasoning, to $\rightarrow$ threshold concepts, to idiosyncratic jargon.

\section{STEP 1. Name Your Discipline.}

Prompt the group to: "Decide what academic learning community you are affiliated with most closely: in the way you generally think about the world, the specific types of questions and topics that interest you, and the way you do research (that you find valid and intellectually productive). Put a name on that."

Form groups based on disciplinary similarity. *If there are solo members of disciplines, have them join a cluster that uses a similar conceptual, ethical, or methodological approach.

\section{STEP 2. Paraphrase Your Discipline.}

Now, give each cluster a [Blank "Disciplinary Crib Sheet"] from which to model the structure of their own [Individual Notes], as they brainstorm the Jargon, Concepts, Data that define their discipline.

Show the group an [Example of completed Crib Sheet] to give a clear sense of how to fill out theirs.

* Emphasize the importance of distinguishing Jargon (field-specific theory-infused, implicit meanings) from vernacular explanations (concrete and explicit enough for a novice to understand) when they translate their Threshold Concepts and explain their Practical Methods of data gathering for the group.

\section{STEP 3. Share Your Discipline.}

Once individuals have drafted their ideas (give them at least 10 minutes), have them compare/combine notes on the discipline, or discipline-cluster, and fill in their group's Crib Sheet (for another 10 minutes observe the groups and give additional time/guidance as necessary).

Once they have a a well-developed Crib-sheet, have them Organize these ideas into a flow, drawing *Explicit connection-lines from the bottom up: Info sources \& Analyzing processes $\rightarrow$ Types of findings $\&$ Key ideas of discipline $\rightarrow$ Specialized language that encapsulates these main ideas for scholars in field.

Finally, have each discipline-cluster present this flow-chart to the group, creating it with [Big Pens] on a [Large Board]. *Give them very little time (3 minutes? Strategically too little time!) to pressure them to be concise and focused, giving a coherent big-picture overview of their field for the novices in the room.

E.G. Preamble: "Today, our goal is to share what we've discovered, and distilled, about the way our different academic disciplines do business, when it comes to building knowledge: what basic assumptions and attitudes they stand on, where and how they go about adding to those understandings, and the language they use as shorthand in expressing those ideas with one another."

"Which discipline-cluster wants to lead us off? Main ideas (make these super-simple) in the center, main methods and data (word these super-concretely) down below, main terms (define them briefly) up top. Organize each level, and connect them together for us: terms, ideas, concrete objects and experiences-help us draw the lines."

\section{Afterward.}

If this activity really engages the group, it will likely lead to many follow-up questions, curiosities, and discussions across the discipline-clusters. This free exploration is great for building group cohesion and building a "common language" for the project. Consider leaving a light schedule for the following meeting, to make room for those discussions. 


\section{Disciplinary Field "Crib Sheet"}

Use this page to write out key terms in your field, conceptual truths and values that are essential to understanding those terms, and methods of compiling and interpreting data to substantiate those kind of truths and values - that define the academic work of your discipline.

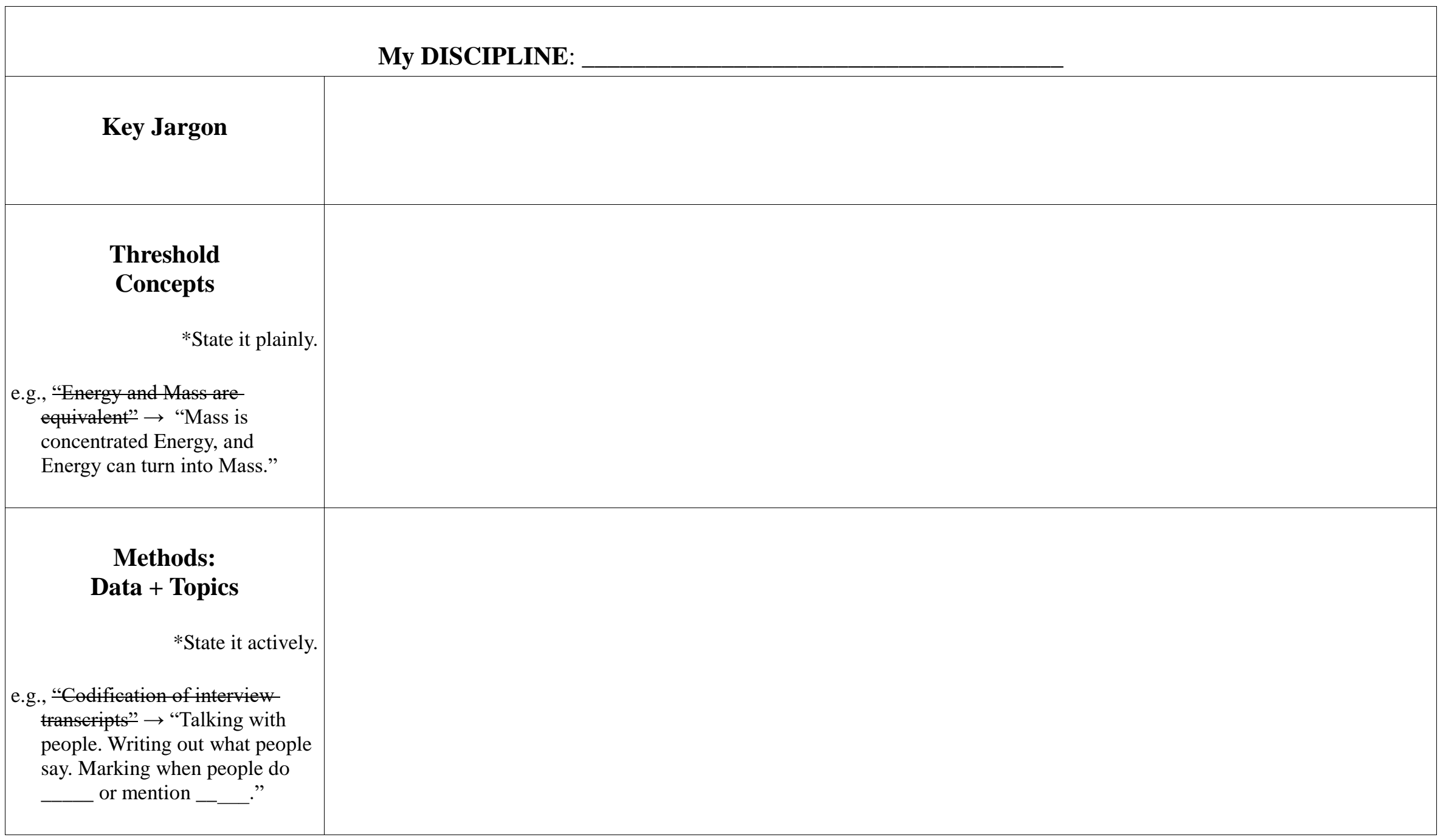




\section{Example Crib Sheet: Education}

\begin{tabular}{|c|c|}
\hline & EDUCATION (Teaching \& Learning) \\
\hline Key Jargon & $\begin{array}{l}\text { "Schema/Schemata" • "Scaffolding / Zone of Proximal Development” • "Rote vs. Deep-Active Learning”• "Transfer / } \\
\text { Generalization"• "Threshold Concepts"• } \\
\text { "Experiential Learning / Learning-by-Doing" • "Situated Learning / Legitimate Peripheral Participation" • "Intrinsic vs. } \\
\text { Extrinsic Motivation"• "Hierarchy of Needs / Self-Actualization"• } \\
\text { "Fixed vs. Growth Mindset" }\end{array}$ \\
\hline $\begin{array}{l}\text { Threshold } \\
\text { Concepts }\end{array}$ & 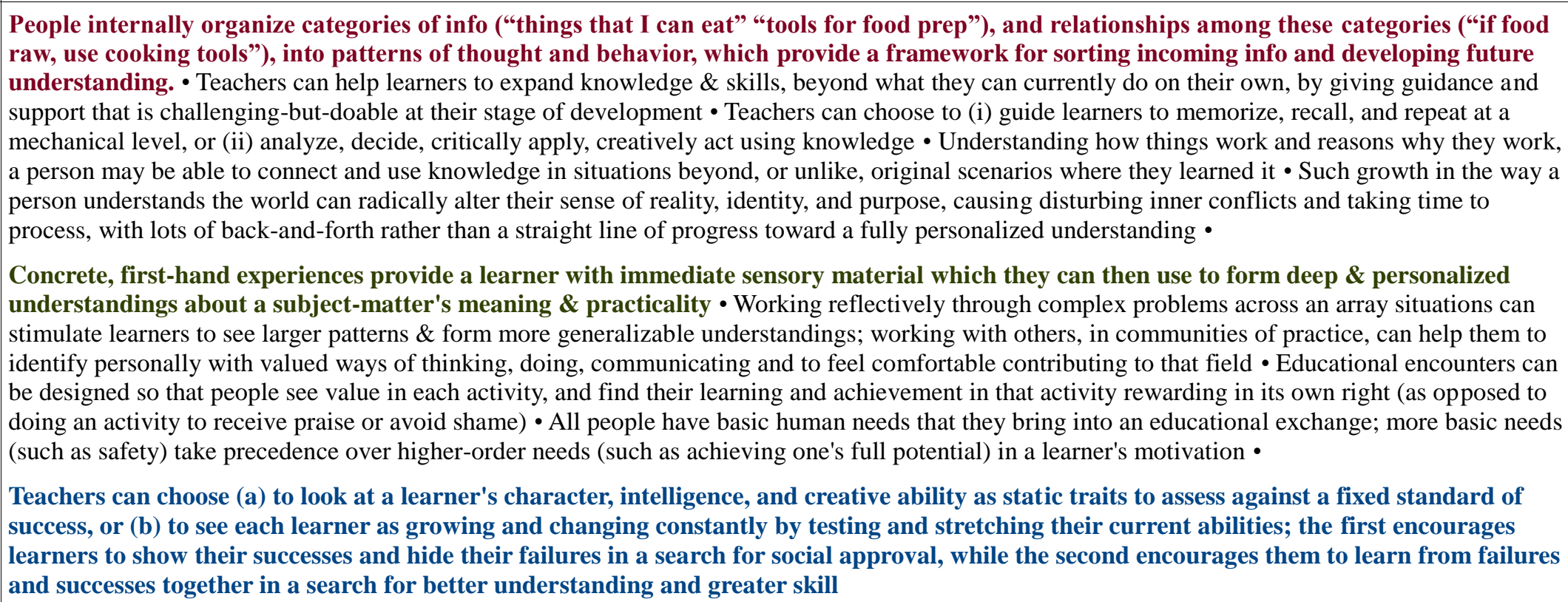 \\
\hline $\begin{array}{c}\text { Methods: } \\
\text { Data + } \\
\text { Topics }\end{array}$ & $\begin{array}{l}\text { Broad topics of Educational Inquiry: How people learn } \bullet \text { What healthy learning looks like, and does for individuals/society } \bullet \text { Effective means for } \\
\text { supporting teachers and students in healthy learning exchanges, toward specific educational outcomes // Fields informing this inquiry: History } \bullet \\
\text { Philosophy } \bullet \text { Sociology } \bullet \text { Psychology } \bullet \text { etc. // Methods adopted from these fields: reading \& organizing accounts/artifacts from past educators \& } \\
\text { institutions } \bullet \text { observing \& interviewing teachers \& learners in current educational exchanges } \bullet \text { collecting large-scale feedback about current educational } \\
\text { approaches \& outcomes via tests and questionnaires } \bullet \text { planning \& implementing educational activities/programs, using tests \& surveys to determine } \\
\text { learning outcomes } \bullet \text { exploring literature from other fields to help inform \& refine fundamental theories of teaching \& learning }\end{array}$ \\
\hline
\end{tabular}




\section{ACTIVITY STEPS: "Disciplinary Crib-Sheets"}

Brainstorm - Give everyone a blank Crib-Sheet for summarizing their discipline. ( $\sim 5$ minutes $)$

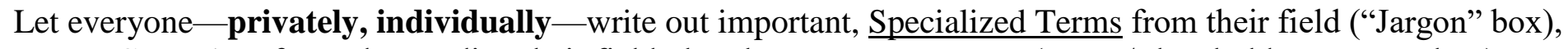

Core Ideas for understanding their field, that these terms represent ("Core/Threshold Concepts" box),

\& basic Methods/Data/Study Topics through which the field has developed its knowledge ("Methods/Data" box).

* As activity leader, before this activity, listen for (and write down) specialized terms that group members use from their own fields as concrete Examples of Jargon.

* In the interest of time, encourage 1st-order thinking: stream-of-consciousness, no ordering or editing, just flow.

* Clarifying: if students have difficulty differentiating what goes in the three boxes:

Jargon = terms that make you go "I'm going to have to explain this, aren't I?" in conversations with friends/relatives outside your field.

Threshold Concepts = ideas/understandings from your field that (A) change the way you see \& interpret the world, and that (B) you have to really know to "be part of" your field \& "talk with others" in your field.

Topics/Methods/Data = "Okay - this is what we do." The Places you go to learn, the Tools and Strategies you use to explore or problem-solve, and the Concrete Stuff/Information that you use to build/refine your ideas, approaches.

* Options: you can assign this page to people as a Take-Home Activity to prepare for the next steps, or you can do it In-Class directly before. In the latter case, just have them focus on the "Jargon" box.

\section{Select \& Order - Sort the class into groups of 3-7, with people from similar disciplines together. ( $\sim 15-20 \mathrm{~min}$.)}

Have each group: Pick 4-5 terms, Order them, and Unpack them (writing out underlying ideas, data, methods in simple language).

Decide (A) what is the most essential Jargon in their field, (B) in what order these terms should go when explaining the field to others-e.g., from Basic realities to Practical details/challenges to ultimate Big-Picture purposes/values/goals, and (C) how to describe those terms to everyone-what each one means and how they all connect together within the field — without using Jargon!

* Priming: As a Leader, you can can create a Crib-Sheet defining your home field, as a Model for groups to follow.

* Timing: keep group dialogs moving: 5 min. "Choose your 4-5 terms, start defining!"; 15 "Who will be presenting?" (e.g., each person describes one term, a volunteer writes on board; or a pair goes up, one talking and one writing)

* Numbers: groups of 4-6 people work well. Focusing in on 4-5 key terms. They can list/order more, but explaining them without Jargon - thinking of a clear defining sentence \& a relatable example for the audience - takes time. 
Share - Bring the groups back together as a whole class, taking volunteers to present their fields one-by-one.

Start by having them write \& explain the terms they selected. If anything is unclear to the audience in that key-of-terms, encourage them to ask for clarification (e.g., "What is the difference between...?" • "How do you get from

"Why _ instead of _ other way?"). From here, group may transition into more open discussion of field methods and knowledge.

* Equipment: Supply a large writing surface or projection-area (\& pens!) on which the groups can display, underline, illustrate their terms.

* Momentum: Keep the Crib-Sheet introductions brief. Aim for 5 minutes per-group, for the initial explanations. (If presenters seem almost rushed by the time-constraint, that is good:) comfortable academics fall into sharing distracting details that fascinate them, whereas time-pressed academics focus on getting across their most important points concisely - before their time runs out.)

* Room for Confusion: some disciplines use the same terms, but in different ways. Some fields explore similar things, but talk about them using different terms.

Talk only about one discipline at a time for the initial presentations, but make time in open discussion for groups to start making those connections across their disciplines' crib-sheets ( 20-25 min. / $5 \mathrm{~min}$. open).

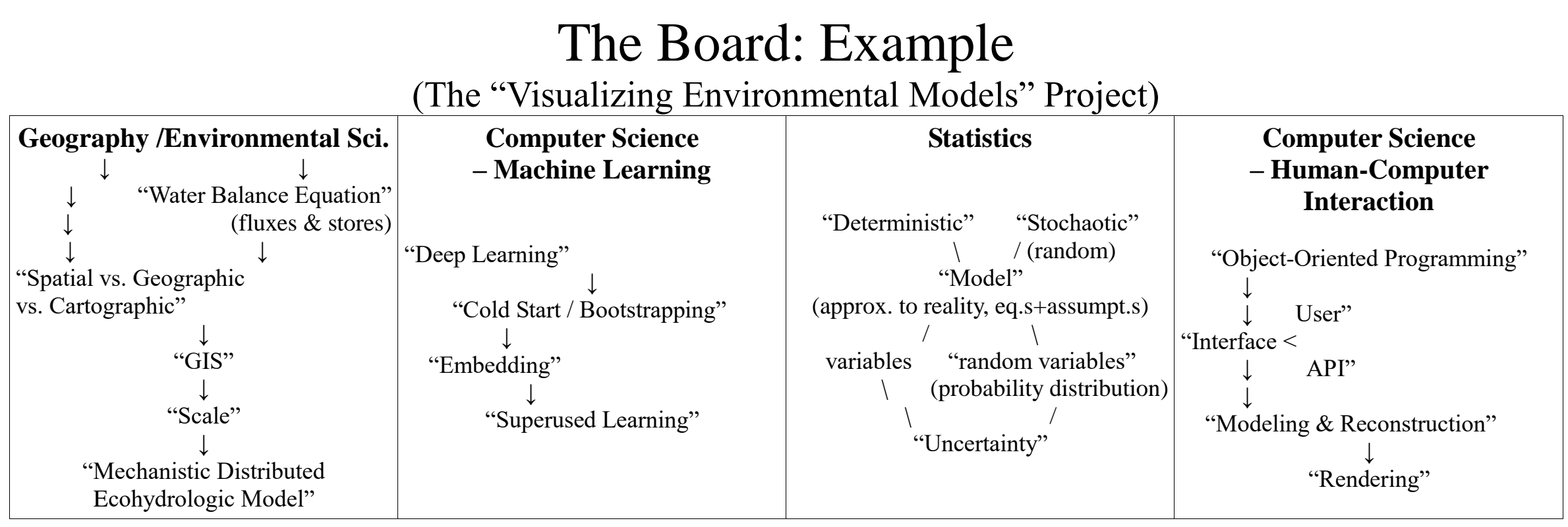




\section{Example "Crib Sheets"}
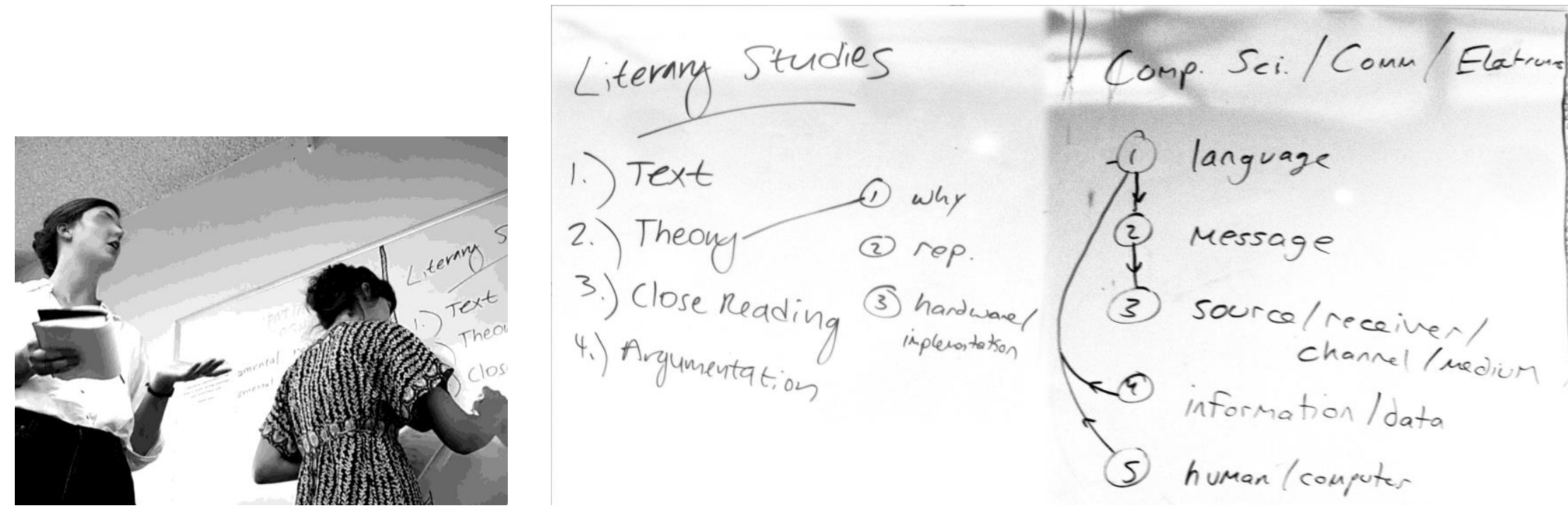


\section{Activity 5. "Be-Do-Make” Grid of Participants' Goals (and Products).}

Description: A structured grid to aid discussion, making explicit the various personal goals of a project participants, to inform specific action plans for research tasks and end products.

WHEN: As the project gets underway, all leaders and participants together.

WHY: To help the group understand one another's personal goals, democratically informing their plans for concrete project deliverables, i.e., "Making sure we know what we're after."

HOW: Board-centered group discussion activity (creating an explicit, organized, inclusive brainstormimage about what faculty and students all hope to accomplish through this research collaboration).

\section{STEP 1. State Your Motives and Ideals.}

Write on the [Board] these words in a vertical column, with lots of space between them and beside them (this is the beginning of a large $3 \times 3$ chart): "Produce" "Do" "Be." Now have everyone bring out [Paper and Pen] and ask them

"What do you want to gain from this project, in terms of:

DOING: personal-professional experience, practice, development

\{exposure, skills, knowledge\};

PRODUCING: tangible, visible, useful objects

\{refined theories/models, recorded experiments/trials, publicly shared prototypes/texts\};

BEING: social standing, identity, purpose as a member of this group -or- your academic community \{opportunities, responsibilities, affiliations; votes/voice, CV-lines, titles\}?"

Independently, have participants write their responses to this. *Be Concrete, and Selfish!

\section{STEP 2. Discuss Possible Plans and Strategies.}

Now, write on the board horizontally (the columns of this $3 \times 3$ chart) "Person" "Group" "Community." Have participants gather into small groups - divided by: Level\{faculty/grads\}? Discipline \{history/art\}? Role\{research, teacher, technician\}? Let group decide - and have each group discuss

“How might this project's goals be translated into practices ... that meet yours and your partners' goals? Acknowledge:

the Personal - what this does for you (the notes you just wrote).

the Interpersonal - what this will do for others in the group/the group as a whole.

the Societal - what this will give those outside: disciplines involved, communities affected, etc."

Have them take notes on their practical ideas (be-do-make), and their intended impacts (person-groupcommunity). * Be Constructive, and Imaginative!

\section{STEP 3. Offer Responses and Adaptations.}

Have the groups come together, and begin filling in the grid. Use [Different Colored Markers] to distinguish groups (or circle, underline, illustrate ... whatever helps order the brainstorm!) as you

Share: Which of these ideas seem most promising, from your cohort's perspective?

Discuss: What adjustments to one another's plans might make them more sustainable, effective, and efficient in implementation? * Be Pragmatic, and Realistic!

\begin{tabular}{|c|c|c|c|}
\hline & Person & Group & Community \\
\hline Produce & & & \\
\hline Do & & & \\
\hline Be & & & \\
\hline
\end{tabular}




\section{ACTIVITY STEPS: "Be-Do-Make" Grid}

(Solo) Be Concrete, Selfish - Motives \& Ideals: Everyone think on your own about the question

"What do you want to gain from this project?" in terms of: ( $\sim 10$ minutes)

PRODUCING: tangible, visible, useful objects for you \{refined models, recorded experiments, publicly shared texts\};

DOING: personal-professional experience, practice, development \{exposure, skills, knowledge\};

BEING: social standing, identity, purpose in this group - or - your community \{opportunities, responsibilities; votes, CV-lines\}?

* Have Available: paper and pens - for writing down, revising these sentences.

* Prompt for Reference: Write on board [ Produce $\backslash$ Do $\backslash \mathrm{Be}]=\{$ vertical $\uparrow$ levels $\}$

\section{(Groups) Be Constructive, Imaginative - Plans \& Strategies: Get into groups and share your} ideals. Discuss "How might this project's goals be translated into tasks/deliverables ... that meet your AND your partners' goals?"

Acknowledge: ( 20 min.)

the Personal - what this does for you.

the Interpersonal - what this will also do for others in the group.

the Societal - what this will bring to the disciplines and communities, those involved and affected.

* Prompt: write on board [ Person $\mid$ Group $\mid$ Community] $=\{$ horizontal $\leftrightarrow$ levels $\}$

\section{(Whole Group) Be Pragmatic, Realistic — Responses \& Adjustments: Bring the whole group} together. Share: What do people in your group want to make sure they're doing, being producing? Which of your suggested project ideas seems most promising, rewarding, feasible at the Personal, Group, World level from your cohort's perspective?

Discuss: What adjustments to one another's plans might make them more sustainable, effective, and efficient in implementation?

* NOW THE BOARD SHOULD HAVE A \# GRID - as cohorts share, start take notes of what individuals want.

* NEXT TO GRID - start drawing out a span of feasible project options, that combine peoples' disciplinary skills/resources. 


\section{Example "Be-Do-Make" Grids: Grizzly Reintroduction Project}

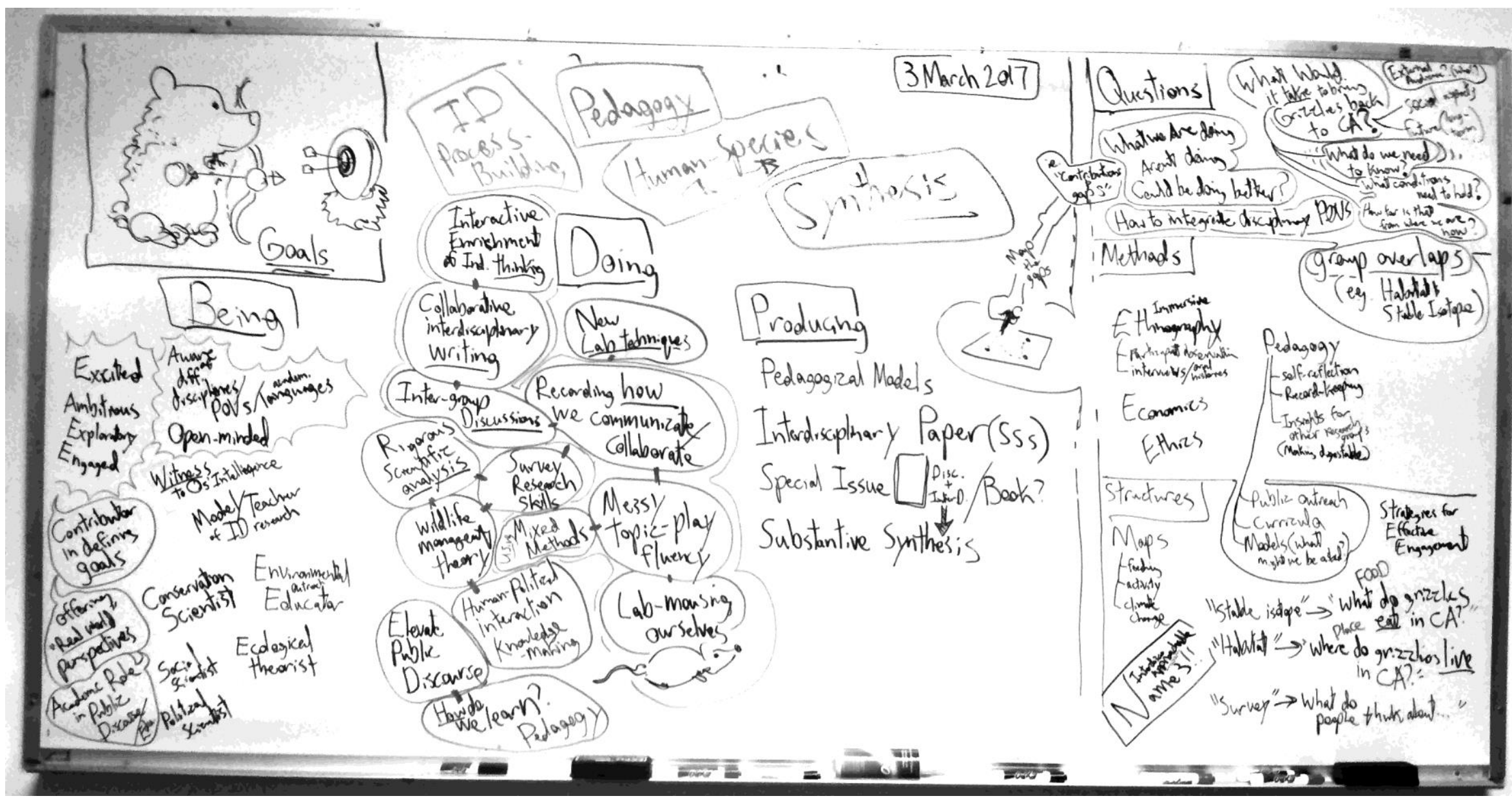




\section{Activity 6. "Dialog Journal” Reflections on Interdisciplinary Research.}

Description: A weekly structured reflection activity to help research participants see patterns and distill principles about coordinating working across disciplines, as they progress in their collaborations.

WHEN: Weekly, as the group work together on the project's action items (reading, testing, producing). WHY: To look at our work together and notice what interferes with/supports interdisciplinary practice. HOW: Descriptive journaling that progresses from concrete retelling of events, to personal interpretations and judgements, to pattern-recognition and naming possible principles for practice.

\section{STEP 1. Story.}

Open a blank text-document or a provided [Dialog Journal Template] page. In the section titled "Story," write about what happened, the flow of events with your project group this week. You may include:

*Setting. location, objects, pre-planned structure, etc.

*Reason/purpose for people coming together.

*Order of Events, connections from one to the next.

* Memorable Details. Things said, done (in "quotes" if particular words stuck in your memory).

*Final Outcomes. How things concluded (emotionally, intellectually, practically).

\section{STEP 2. Narration.}

In the next section, titled "Narration," write about your personal perspective of these events. Where the first section is objective description (i.e., 'This Happened') this section is your experience:

*Feelings about this environment (things you appreciated, things you disliked).

*Feelings about gathering's goals and meanings (valued things, wasteful things).

*Energy of the process (people connected, disconnected; understandings common or separate)

* Responses to Details (why these moments were surprising, disheartening, special, consequential)

* Reflective Judgements (things that worked, things you would change-and maybe how)

\section{STEP 3. Patterns.}

In the next section, "Patterns," briefly write down any patterns or themes that you're beginning to notice (i.e., 'X happens every week, and I can now predict that it will end one of these ways...') in:

*People (character traits; types of reactions; strong identities, affiliations, attitudes, motives that arise in these events)

*Events (approaches that people seem to do well with, structures and tools that help the project move forward)

*Ideas (insights and understandings that, when shared, seem to support group cohesion, learning, and productivity)

\section{STEP 4. Principles.}

In this final section, "Principles," write any general lessons or ideas that might support future practice in interdisciplinary groups (i.e., 'Providing X helps people to do $\mathrm{Y}^{\prime}$ or 'If you don't have X, then Y falls apart). You can re-write and refine these general notions or claims, each week; the point here is simply to take a minute after journaling about your group's experiences and reflect on the big picture:

*What seems to be true? (about people, objects, actions or relations in these situations)

*What seems to follow from these truths? (what works, what undermines; what is dependable, if $\rightarrow$ then)

\section{Example sentences:}

Story - "We met in a warehouse to discuss 'Love.' John began with a dictionary definition, then we all took turns responding - Abby said, 'I think love is about care, acceptance, and understanding, but people short-change the last two.' Billy added, 'because those require effort. Anyone can care, but it takes humility to accept and work to understand.' The talk got cut short because the room was cold—Jaylyn said, 'Whoever picked this location clearly does not love us.' And we disbanded."

Narration - "I think the definitions John offered were a good launch-point: it was important that he introduced them as grist for us break apart and build on; that emboldened me to share my own ideas and question others. Cold room = BAD idea!" Patterns - "People seem to follow the leaders' example, when it comes to the tone they set (open listening, collaborative idea-shaping). But environmental details (like venue) can really distract from that progress."

Principles - "Comfort supports conversation." 


\section{Dialog Journal Template}

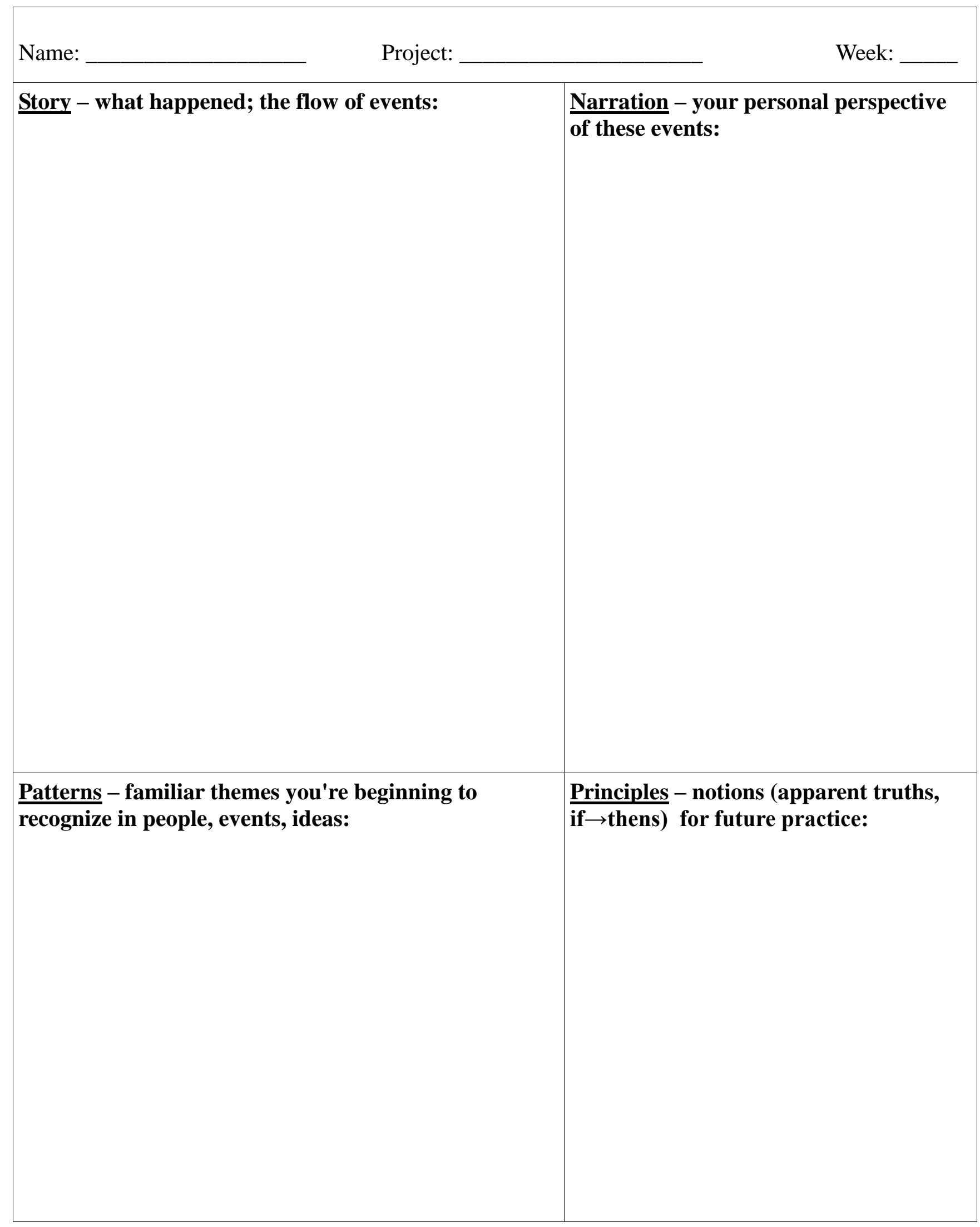




\section{Example Journal Entries: Green Chemistry Project}

\begin{abstract}
Story:
"We were assigned to look through the textbook as homework for Thursday." (Week 4)

"The idea was to basically to a 'deep dive' (as said by Dr. M) into the supply chain and life cycle of polyethylene. That is, we were tasked with "If finding out all we could about the polymer, starting from where all the raw materials came from to what happens to the polymer at the end of its life. We really had to plunge into numbers corresponding to volumes and the rest of the class for two weeks, then gave a final 15 minute presentation." (Week 4)

"Before presentation, we met in the chemistry building, discussed the contents and concluded that what we prepared is enough to introduce important information about PET. During the presentation, Dr. M asked us a lot of really challenging questions to get us to know, to be aware and to be informed" (Week 5)

"Each group gave a presentation regarding to the detailed contents based on various topics: rare earth metal recycling, reverse osmosis, properties of liquid-water supercooling and transition-metal catalysts, etc. Then we picked 3 topics that have good connections to either Chem $1 \mathrm{C}$ course contents as well as environmental sustainability." (Week 6)
\end{abstract}

\section{Patterns:}

"Professors love to talk and can get excited quickly. People do not like change when they must change themselves, but they like to talk about how others should change." (Week 4)

"When you put a bunch of like-minded people in a room, you get a lot of like-minded answers that can reinforce inaccurate beliefs about the world. People like to try to help and are good at identifying problems but not solving them. I've learned that I do not enjoy participating in sedentary activities such as sitting in a lecture to hear people talk. I would be more enthusiastic about interactive activities." (Week 6)

\section{Narration:}

"When we realized as students that it is extremely hard to get some data (energy or price), we didn't know how to deal with these parts on our own" (Week 4)

"If I had to prepare this presentation alone, I would make a good presentation. But, since I worked with people who have diverse

expertise, I think we were able to add more valuable information

and make better presentation. In addition, while working together, I was able to learn more." (Week 4)

"I don't like group projects. It's always worrying if other students are willing and able to perform at the level you would perform at ... I

feel like I'm the old man yelling 'get off my lawn.'" (Week 5)

"This week allowed us to reflect upon the rather stagnant type of environment that we are creating for freshman chemistry students, and pressed upon how important it is to look at science through a fresh new perspective." (Week 5)

"Looking at the other presentations, too, I was fascinated by the sense of the sheer volume, utility and subsequently danger of using plastics in our day-to-day life." (Week 6)

\section{Principles:}

"What seems important is to keep an open mind."

(VALUE - ask: open about what? how does this help the group?)

"Fresh perspectives are required for growth."

(IF $\rightarrow$ THEN - ask: whose views? How to use? For growing what?)

"Escaping from your own reality is hard."

(PRACTICAL ISSUE - ask: What helps you expand beyond your own reality, in this group?) 


\section{Dialog Journal Template (Group Leaders' Version)}

WHEN: Monthly as the project progresses. WHY: To chronicle the group's and individuals' progress within the seminar. HOW: Dialogic journals recounting group goals, discussions, and individuals' notable struggles or successes.

\section{INSTRUCTIONS:}

Each month, take 15-20 minutes to describe:

(A) what's happening in your courses - current class learning goals, activities and outcomes.

(B) conversations you're having with students - what are they interested in, asking you about, confused by, needing help with.

(C) how you and others are using your various disciplinary expertise as leaders to model academic teamwork for the group what experiences or insights (from your own, or invited peers', research), skills or strategies (from communicating across disciplinary boundaries), have you shared or demonstrated to answering students' questions.

(D) participants' observable experiences in contributing to these interdisciplinary conversations and tasks - how are they responding to other disciplines' ideas, methods, and attitudes within the research group. Specifically:

Working in a team with people from other disciplines.

Communicating research from one field to people trained in different disciplines.

Recognizing and articulating the comparative strengths of multiple disciplines.

Applying approaches and tools from these other disciplines to address a current research problem.

No need to over-think these entries. They are journals; their value comes from being consistent and looking at the progress in your thinking over time.

\begin{tabular}{|l|l|}
\hline \multicolumn{1}{|c|}{ Name: } & This Month's $\underline{\text { Conversations }- \text { Interests, Questions, Need Help with: }}$ \\
\hline This Month's $\underline{\text { Story }}$ - Context, Activities, Intentions: & Project: \\
\hline $\begin{array}{l}\text { This Month's Leadership - Helping with our Skills, } \\
\text { Experience: }\end{array}$ & $\begin{array}{l}\text { This Month's Participants - Collaboration, Struggles, Acheivements, } \\
\text { Learning: }\end{array}$ \\
\hline
\end{tabular}




\section{Dialog Journal Template (Teachers' Version)}

WHEN: Weekly as your interdisciplinary course progresses. WHY: To chronicle students' progress within the seminar. HOW: Dialogic journals recounting lesson/activity goals, use of different fields' lenses/tools, group questions and discussions.

\section{INSTRUCTIONS:}

Each week, take 15-20 minutes to describe:

(A) what's happening in your courses - current class learning goals, activities and outcomes.

(B) conversations you're having with students - what are they interested in, asking you about, confused by, needing help with.

(C) how your project's interdisciplinary work is being integrated in the class - e.g., as literature and case-studies for students

to learn from, as raw data and method-heuristics for students to try, etc.;

(D) how you use your expertise to make interdisciplinary ideas more personal, approachable, relatable for students - what experiences (from your research/discipline OR from others), skills and strategies (from communicating across disciplines), have you shared with students or applied when answering their questions.

No need to over-think these entries. They are journals; their value comes from being consistent and looking at the progress in your thinking over time.

\begin{tabular}{|l|l|}
\hline \multicolumn{1}{|c|}{ Name: } & \\
\hline Context/Activities - what's going on in class right & Educational Dialogs - what are students interested in, needing \\
\hline now: & \\
\hline $\begin{array}{ll}\text { Interdisciplinary enrichment-how you are using } \\
\text { content from research projects to enhance lessons: }\end{array}$ & $\begin{array}{l}\text { Your expertise - how are you using your experiences, skills } \\
\text { from collaborating in these projects to help students learn: }\end{array}$ \\
\hline
\end{tabular}


Disseminating Stage

Activity 7.

"Making of knowledge"

Research-cycle Flowchart.

Activity 8.

"Good Cop, Bad Cop"

Team-Teaching Role Play Lab.

Activity 9.

"Eight Frames"

Communication with Audiences Storyboard.

Activity 10.

"Interdisciplinary Principles Reflection"

Synthesis of Experiences and Insights Journal. 


\section{Activity 7. "Making of knowledge" Flowchart.}

Description: A research process flowchart to help students explain the steps their disciplines take in turning complex, organic realities into discrete, structured idea-frameworks.

WHEN: As participants begin preparing to share their interdisciplinary research, knowledge, or experiences with novice audiences (students, the public).

WHY: To practice explaining the strengths and boundaries of knowledge-building in each discipline. HOW: Analytically describing the steps of producing knowledge in one's own field-including the challenges, benefits, and limits of that approach — and making a map to help summarize that cycle people outside your field.

\section{STEP 1. Describe your Level of Experience in your Field.}

On a blank sheet or [Research Flowchart Handout], begin by listing the research methods, in your field of study, that you understand well enough to:

(a) feel comfortable doing;

(b) feel comfortable describing, and could do with a little prep or help; or

(c) know that the method exists in your field, but aren't well-versed in yourself

\section{STEP 2. Three Memorable, Valuable Pieces of Research.}

Now, in the next section, think of a few studies from research literature in your field that stand out in your memory as really valuable (well-researched, well-presented, important/interesting findings). Describe:

What methods they use.

What sources they seek (people, places, things) for evidence.

How they extract/organize data from these sources (collection processes/actions/tools).

What data this provides them (that product's form/function).

What they do, analytically, with this data (interpretation processes/actions/tools).

What findings they draw from this process (information about [a phenomenon], knowledge on [a topic], theories of [a big-picture concept],).

\section{STEP 3. Challenges and Limits of Research.}

Reflect on your own research experiences (e.g., coming up with a question, designing a protocol, collecting and analyzing data, looking for something worth saying in those results) and those of others. Put a human face on these research approaches - the challenges and limits of Sources, Data, and Reality within your field:

Describe the realistic (potentially problematic) attributes of your research Sources, Data, Selective Aspects of Reality.

List some of these problems that you've seen or experienced regarding Collection (e.g., contaminating source-material), Analysis (e.g., corrupting data), Findings (e.g., biasing analysis, over-reaching claims).

Name some of the boundaries for these methods: outside of what they show really well, what do these Sources, Data, Selective Aspects of Reality not allow you to see into well?

\section{STEP 4. The Question-to-Questions Cycle of Research.}

On a [Big Blank Page], draw a picture that illustrates the research experiences you've outlined above- the practical flow:

from motives/ideas (the for-whom \& why), to plans/strategies (the where/when \& for-what), to actions/responses (the how), to findings/boundaries (the next layer of why...)

in building out a knowledge-field - dotted with challenges, surrounded by external factors that press in on that flow. Make it clear for yourself, so you can make it clear for your students: this is research.

(In my field. At this point in history. As I have experienced it). 


\section{The Real Story of "Making Knowledge"}

\section{(Research Flowchart Activity)}

Every Knowledge-Field has, by trial-and-error, developed specialized ways of researching questions about *some aspect of* human reality. Each Field's way of researching a question - and working toward a fuller, more accurate understanding of that topic - has particular strengths (what that type of inquiry highlights, isolates, distinguishes, or connects) and particular limits (its blind-spots, biases, distortions, unexamined edges).

As a Member of your field (however recent or established) you have seen these issues playing out - in literature, labs, sites of research. This experience makes you a valuable asset to your students, in conversations about research: what it is, how it \{or the lack of/need for it\} impacts their lives, what types of questions they're interested in, what types of research might be used to explore those topics or issues, and why MANY fields are needed to create a full picture of any real-world issue.

*Leading those conversations begins with you acknowledging where your expertise lies—and the boundary lines, beyond which you are still a learner. Showing both sides of your expertise (specific knowledge; limits of knowledge) sets the tone for an interdisciplinary learning environment: honest, explicit, humble, respectful, collaborative,

supportive. So make sure you are ready to do that, when the moment calls ... Making a map might help you:

\section{Step 1 - "Off the top of my head..."}

Warm up your brain by listing off research methods, in your field of study, that you (a) feel comfortable doing; (b) feel comfortable describing, and could do with a little prep or help; and (c) know others do in your field, but aren't well-versed in yourself.

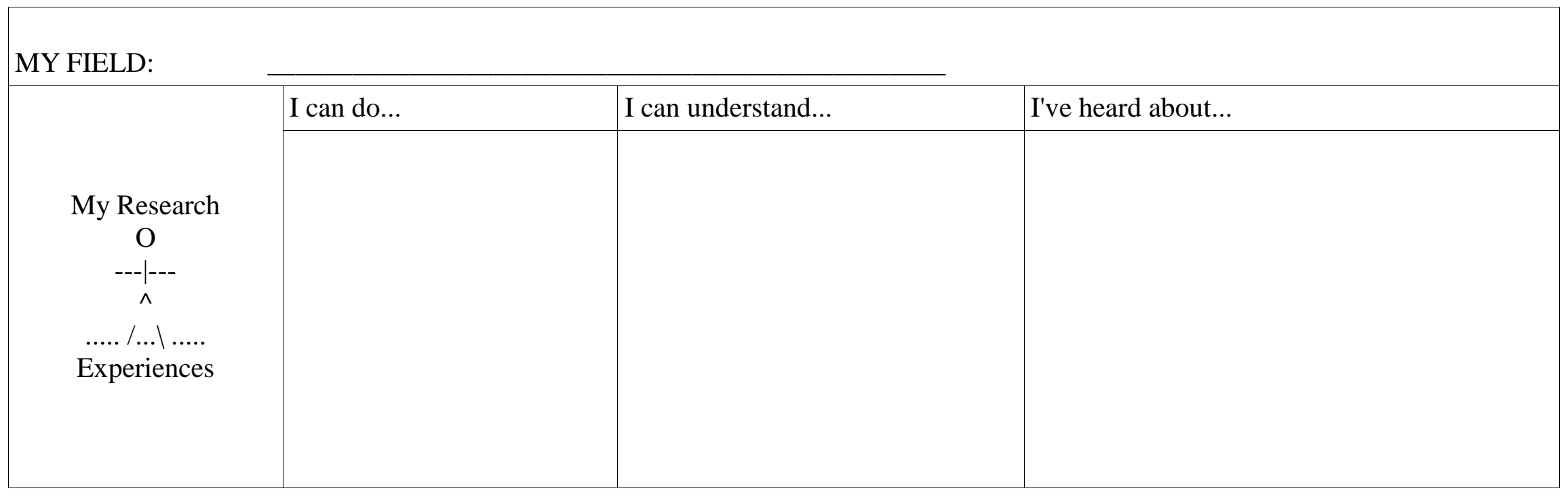




\section{Step 2 - "A few of my favorite (researched) things."}

Which studies that you've read, in research literature from your field, stand out to you? *Ones that you see as really valuable (well-researched, well-presented, important/interesting findings). What methods do they illustrate? What sources (people, places, things) do they seek? By what processes (extraction tools/actions) do they collect data from these sites? What kind of data (its form, function) does this give them? What do they do, analytically (interpretation tools/actions), with this data? What sort of findings (information about _ _ phenomenon, knowledge on topic, theories of big-picture concept) do they draw out from this process?

Here! Use this chart to tell the story of that basic protocol:

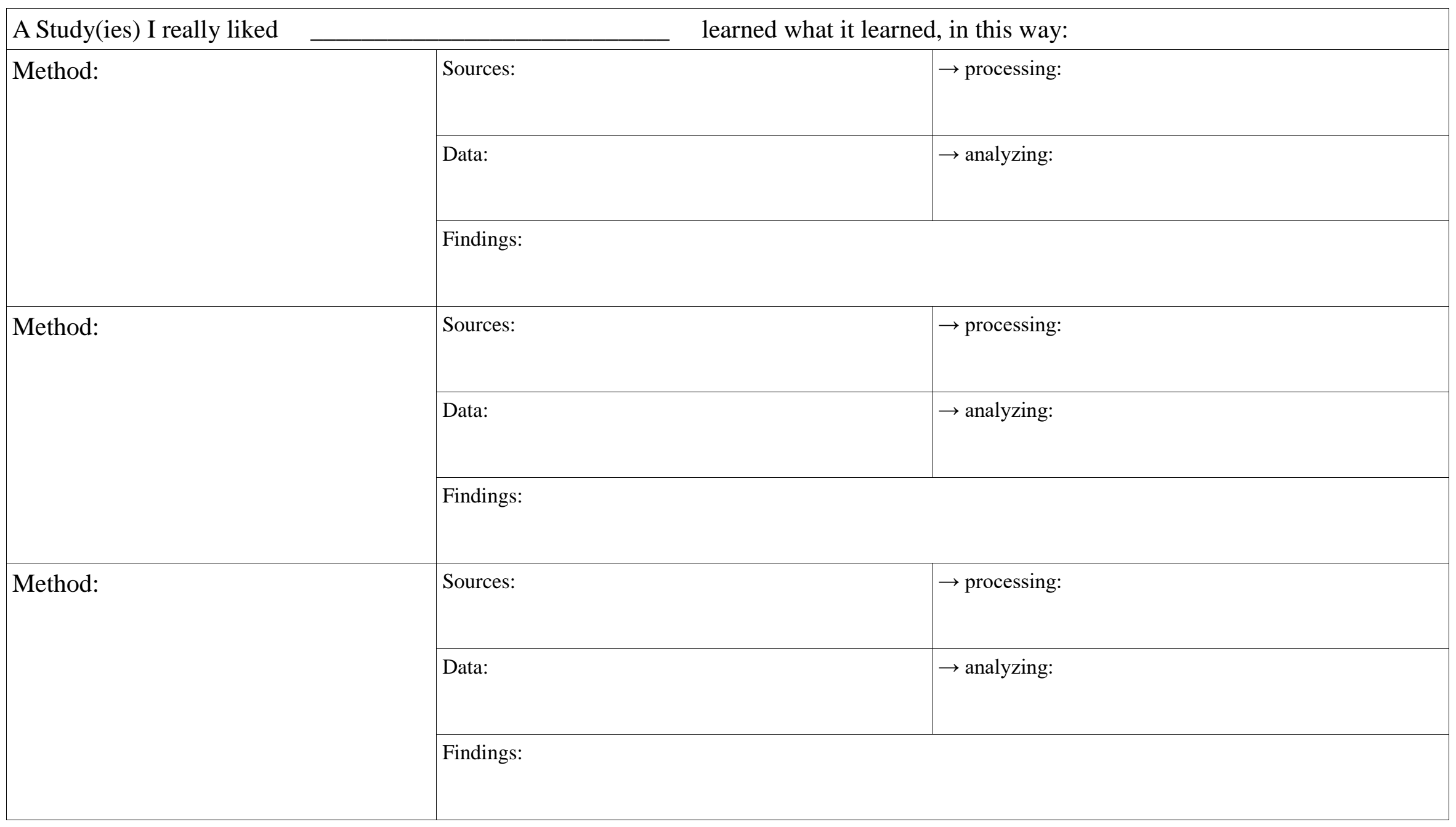




\section{Step 3 - "A closer look."}

Presumably, you've done some of these types of research, yourself: come up with a question, designed a protocol, collected and analyzed data, looked for something worth saying in those results. Put a human face on these research approaches - what potential problems do you see, and have to avoid (contaminating source-material, corrupting data, biasing analysis, over-reaching claims)? List some of these problems that you've seen or experienced. What are the boundaries of these methods: outside of what they show really well, what do they not allow you to see into well?

Use this chart to guide your reflection through research experiences-first-hand, or that you've seen in the work of those around you:

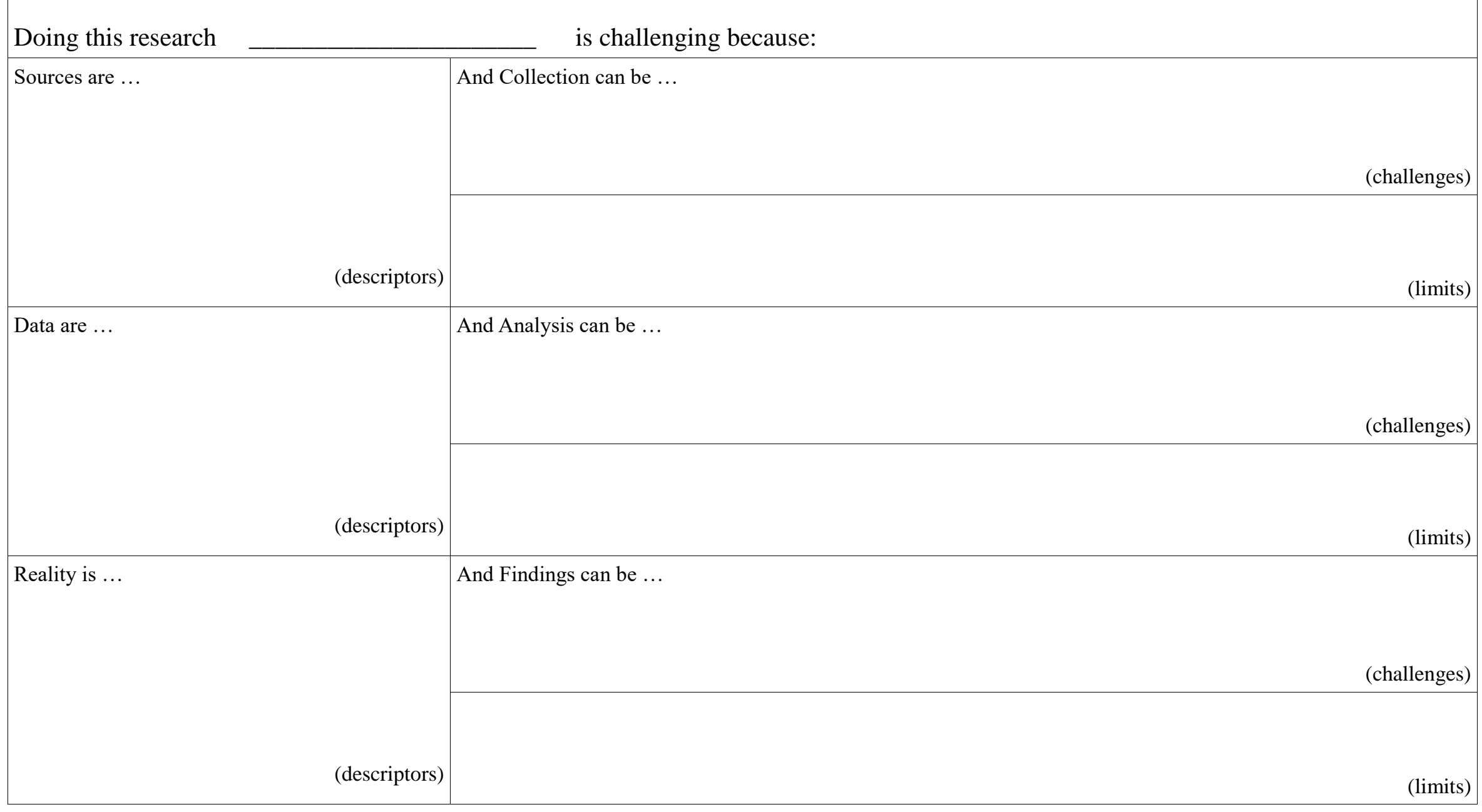




\section{4 - "Bringing it all together."}

Draw a picture on a blank page (you can sketch out initial ideas on the image below), that illustrates the research experiences you've outlined in Steps 1-3: the flow of practical actions from initial research motives/ideas (the for-whom \& why), to plans/strategies (the where/when \& for-what), to actions/responses (the how), to findings/boundaries (the next layer of why...) —all dotted with challenges, surrounded by external factors that press on, complicate, put limits on that flow.

Make it clear for yourself, so you can make it clear for your students: this is research.

\begin{tabular}{|c|c|}
\hline External factors... & [ Illustrated ] \\
\hline $\begin{array}{c}\text { My Research } \\
\mathrm{O} \\
---\mid-- \\
\wedge \\
\ldots . . . . . . . . . \\
\text { Experiences }\end{array}$ & 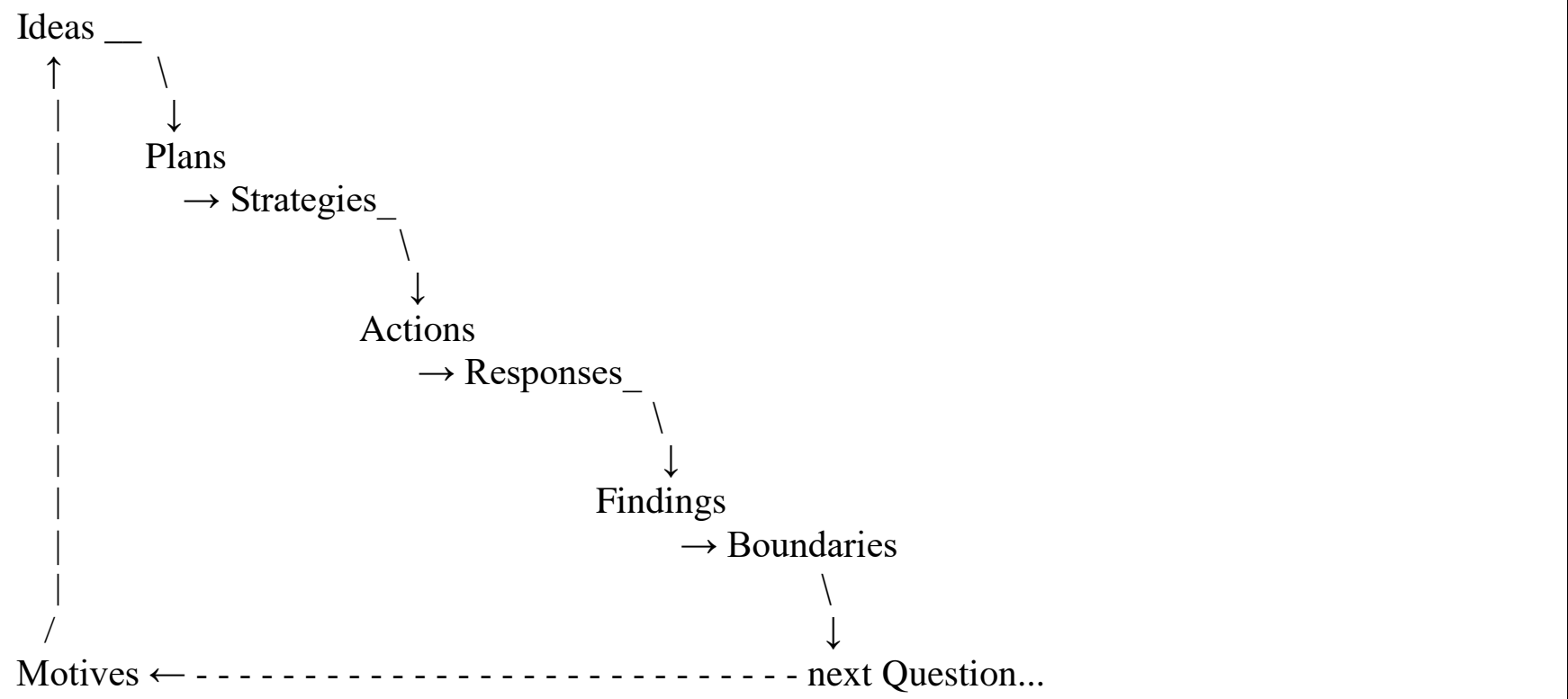 \\
\hline Intrinsic challenges... & \\
\hline
\end{tabular}




\section{Activity 8. “Good Cop, Bad Cop” Team-Teaching Role Play Lab.}

Description: A team-teaching role-play lab to help educators troubleshoot their strategies for communicating interdisciplinary work to novices, and responding to audience questions in a prepared and persuasive way.

WHEN: As participants prepare to work with students in classrooms on interdisciplinary topics. WHY: To practice working with students' beginner attitudes and ideas about interdisciplinary research, using resources we've created to focus and clarify these educational exchanges.

HOW: Role-playing as Teachers and Students, imagining potential struggles, and testing strategic approaches for (a) answering questions quickly and satisfactorily for students, while (b) keeping to your main point.

\section{STEP 1. "Lesson Plan."}

Grab a partner. The two of you are now a teaching team. Pick a topic, related to your disciplines (that both know in common, or each understand an aspect of), to discuss with your "class" (i.e., rest of the group).

* Choose a topic you enjoy, and can sell to us (your students) as interesting/important!

* In your lesson, explicitly discuss the value of bringing together multiple disciplines' (A) perspectives, (B) approaches, and/or (C) methods. Help students see how the fields involved help one another to more deeply (a) perceive different aspects of the issue/problem, (b) analyze and think through potential roads to address that issue, and/or (c) collect information and utilize data to inform and support practical progress regarding that topic.

* Map out the main points you want to make, and any examples/analogies/questions you will use to drive home those points for a non-specialist audience. Aim to "teach" for about 5-10 minutes.

\section{STEP 2. "Classroom Time."}

Teach us (we are your "class"). Each of us will choose to be one of two types of (open gender) students: Dawn/Don the Dreamer, and Bobbie/Bobby the Bullhead. As you teach, we will use the sample [Disciplinary Novice Questions] to think of questions and comments that will challenge you to be clear and stay focused on your main point.

As Teacher 1, your job is to (1) show understanding and respect for those students' novice ideas as thoughtful and genuinely felt, while Teacher 2 (2) clarifies the Reality of interdisciplinary research collaboration, explaining reasons why events play out differently than a novice might imagine. As a team, transition from showing students they're understood to explaining what further realities they need to understand.

* Switch Roles! Trade between being the "Good (Empathetic, Respectful) Cop" who sees and voices what is valid and relevant in students' tangential points, and the "Bad (Assertive, Direct) Cop" who steers that topic persuasively back toward the main points of your lecture.

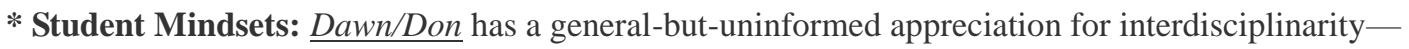
and feels resistant to the notion of "going deep" with any one field's approach or vision, for fear that "marrying" into one discipline undermines the open-minded utopia of being with ALL disciplines $\{\mathrm{Mmm}\}$. Bobbie/Bobby rolls eyes at most disciplines, except one (their favorite one) - and thinks that other disciplinary perspectives are less valid and interesting (conceptually/morally), less useful and relevant in life (practically), and/or less rigorous and predictive in their findings and models $\{$ OoOoh\}.

* Key Points to consider explaining for students: the necessity of discrete disciplinary specialties withIN a collaborative utopia; the complimentary work that different approaches bring in creating a stronger, more complex and accurate view of a research topic; and the challenges and rewards intrinsic to that cross-cultural building of knowledge - as you have experienced it.

* Use your resources: the journals, maps, and notes you've created-they're part of your resources for teaching now! (e.g., Knowledge-Making Flowchart, Disciplinary Crib-Sheet, Dialog Journals) 


\section{Disciplinary-Novice Questions}

Sample Questions - from Idealists (Dawn/Don):

- How does this approach incorporate the perspectives of (unrelated/irrelevant here) field?

- If this approach to this problem is mostly using and perspectives, how is it truly "interdisciplinary" in the full sense of the term? That's just two disciplines.

- If you're asking us each to look at this problem from a certain specific discipline's lens, isn't that working against being interdisciplinary?

- I don't believe in pigeon-holing myself in one specific discipline's dogma-where do I go to get research experience with true interdisciplinary academics?

Sample Questions - from Skeptics (Bobbie/Bobby):

- This approach doesn't utilize (my favorite) method, questions/ideas, conceptual lens. That would make this better.

- This problem could be addressed using (my favorite) disciplinary tools and frameworks alone. Why does it need to force in these other laborious perspectives?

- Maybe these other perspectives bring in good initial questions, but (my favorite) one discipline's methods of research and reporting would be much better at following through and providing answers to those questions.

- The (my favorite) strategies for thinking through problems and methods for researching topics are well-structured and time-tested for dependable / reproducible / useful results. Why do I need to know about these other fields' methods — that I'm not interested in, and that I'm already well-equipped without?

\section{STEP 3. "Teacher Meeting - How was Class?"}

Once all groups have taught — and everyone has been both an expert Teacher and a novice Studentdiscuss what went well, what was challenging, what did and did not help in addressing those challenges $\ldots$ and what teaching principles you can take away from that, for the future.

* Be specific! Remember what students asked; analyze what made it distracting/off-putting or otherwise hard to turn into a teaching moment, and direct back to the lecture. Remember what you said; what well-chosen words, logical connections, or concrete examples helped bridge the gap between the students' minds and yours?

* Generalize! What notes-to-self can you take away from this, for the next time you're in a position to explain complex interdisciplinary work to a group of disciplinary beginners? 


\section{ACTIVITY STEPS: Team-Teaching Role-Play}

Lesson Plan - Grab a partner. Plan out a mini-lesson (about 5 minutes long) on a topic, related to your disciplines, that you enjoy! to discuss with your "class" (i.e., rest of the group). In your lesson, help students to see how bringing together multiple disciplines can (A) highlight different aspects and nuances of an issue, (B) offer multiple ways to analyze and think through ways to address that issue, and/or (c) provide additional sources of data to inform and support that research. Map out the main points you want to make, and any examples/analogies/questions you will use to drive home those points for a non-specialist audience. ( 10 minutes to prep)

\section{Classroom Time - Introduce your lesson, and then take questions. Decide who each of you will be: Teacher 1 is to} show understanding and respect for students' novice ideas as thoughtful and genuine, while Teacher $\mathbf{2}$ explains the reasons why the Reality of interdisciplinary research collaboration plays out differently than a student might imagine. As a team, you'll transition from showing students they're understood to explaining what further realities they need to understand.

As a class, the rest of us will choose to be one of two types of (open gender) students: Dawn/Don (idealist), and Bobbie/Bobby (skeptic). As you teach, we will ask questions and comments that will challenge you to be clear and stay focused on your main point.

\section{Sample Idealist Questions:}

- How does this approach incorporate the perspectives of (unrelated/irrelevant here) field?

- If this approach to this problem is mostly using and perspectives, how is it truly "interdisciplinary" in the full sense of the term? That's just two disciplines. Isn't looking at this problem, from a specific discipline's lens, working against being interdisciplinary?

\section{Sample Realist Question:}

- This approach doesn't utilize (my favorite) method, questions/ideas, conceptual lens. That would make this better.

- This problem could be addressed using (my favorite) disciplinary tools and frameworks alone - which are well-structured and time-tested for dependable, reproducible, useful results. Why does it need to force in these other perspectives? They seem unnecessary.

Teacher Meeting - Once everyone has been both in both roles—an expert Teacher and a novice Student—discuss as a group what went well, what was challenging, what helped in addressing those challenges, and what teaching principles you can take away from that, for the future. ${ }^{*}$ Be specific! Remember what students asked; analyze what made it distracting/off-putting or otherwise hard to turn into a teaching moment, and direct back to the lecture. Remember what you said; decide which well-chosen words, logical connections, or concrete examples helped bridge the gap between the students' minds and yours. * Generalize! What notes-to-self can you take away from this, for the next time you're in a position to explain complex interdisciplinary work to a group of disciplinary beginners? 
Description: A comic-style illustration activity to help presenters condense their messages to one vivid sentence, explained by a coherent visual narrative of essential elements and moments.

WHEN: As group members prepare to present interdisciplinary work to mixed expert audiences (e.g., at conferences or in publications).

WHY: To craft a story that is accessible to multiple single-discipline perspectives.

HOW: Distilling the most important points of a complex project to a single sentence, and illustrating the progress of those elements together in eight (or fewer!) image panels.

\section{STEP 1. The Point (One Sentence).}

Everyone take out [Scratch Paper] and a [Pen]. Fold your paper into 3 equal parts—-top, middle, bottomand start writing about your work, in 3 stages:

<> Verbs, nouns, phrases: what *most important* terms do you need to tell your story?

* Think about your story's topic, as concretely as possible. What are you looking at (places, things, people, events, interactions, patterns)? From what angle (theoretical perspective, practical concern)? With what tools (field recorders, microscopes, computer simulators, historical logs)? To find/explore/expand what detail (something focused, definite, important to you)? To change or improve what in the world (a common idea, definition, attitude, belief, practice)? WRITE! Stream-of-consciousness, simple concrete, non-linear, clumped and/or scattered, all over the top $1 / 3$ of your page.

\section{<> State the main point of your paper in 1 sentence.}

* If it's hard to write out your complex sentence from a cold-start, try starting with a series of your single words and/or simple sentences: write them down, think about how they relate, and assemble them into a more complex sentence that captures your point. (not all the details, just the essence.) Draft/edit/crossout/re-arrange this sentence into something you like, in the middle $1 / 3$ of your page.

\section{<> Summarize the story leading to that point in a stream-of-consciousness paragraph.}

* Look at all the parts you listed, relating to the main point. Don't think! Just start writing: what is true, what is important, what have you learned? What's the problem, where is more/better needed, how can this work help? What do many people not know/misunderstand, how do you clarify/define this idea, what makes it valid/trustworthy... State the Potent Facts, Relevant Situations, and Defining Details that make your topic compelling (i.e., that persuade someone with fresh ears: "I should listen to this"). Write this out in the bottom $1 / 3$ of your page.

\section{STEP 2: The Journey to that Point (8 Frames).}

Now everyone will need a [Large Sheet of Paper] and [Mid/Large Sized Sticky Notes]. Pick up your pen:

\section{<> Prepare the story space.}

* At the top of your large sheet of paper, copy (from your drafting page) that 1-sentence summary of your work as a guiding mantra.

\section{<> Break the story into visual moments.}

* Now read over that sentence, and your paragraph that outlines the story/journey leading to that central thesis, and start illustrating the key moments inside this narrative: they can be from your perspective (a personal "Aha!" moment) or a universal one (an archetypal real-world situation), framed around a small detail (a single neuron sparking) or a broader situation (a city filling with traffic), showing objective realities (an adult intensely scolding a child) or subjective experiences (a fiery monster reflecting in that child's eyes). Draw each moment on a sticky note, capturing the essential points in whatever visual way you think is clearest. (Rely minimally on words, here.)

\section{<> Group the moments and boil them down to 8 main ones.}

* Some of your moments may be a string of First-Then-Next scenes, or a clump of These-Details-AllLead-To-X, or parallel tracks of While-This-Here/Also-That-There, or a contrasting dialog of A-ValidPoint/But-On-The-Other-Hand. Can you combine or boil-down these moments into a more synthetic single image? Is there one moment in a clump that communicates most of the meaning on its own, even if the others are removed? Look at your main thesis again and think about what is essential: narrow down your note-cards into 8 essential frames. 


\section{STEP 3. The Order of Frames.}

Now that everyone has their key elements selected, start arranging and composing them visually in a manner that fits the content, that reflects the movement and energy and emphasis, of the story. Use a tabletop or the "big sheet" itself to plan this layout:

\section{<> What comes first? First frame.}

* Take a step back from what you know; slip into the fresh mindset of a learner, hearing your story for the first time. Where do you start? Not necessarily what comes first chronologically, but what is the first image you want to immerse your audience's mind in? Is it a big picture that sets a scene? Is it a powerful emotional/visceral/vivid action that persuades their personal investment? Is it a relevant end-point that highlights the purpose or ideal outcome of your work? Or is it a clearly defined object that signals to them your topic? Decide on what base you want to build up your audience's understanding.

\section{<> What will keep them here? Middle frames.}

* Time will probably guide your arranging of many frames (clearly, X leads to Y). But let a few other principles also inform the order that you decide on for these middle frames.

First, what is important? If the audience stops listening mid-way (because the room catches fire), what do you want to make sure they leave there thinking about? Get to that as soon as possible. You can add details later, that fill in and enrich ... but start with the big, valuable nuggets.

Second, what is convincing? If the audience agrees with you, "This is valid, useful, relevant-to-me information," then they will pay eager and respectful to you as you speak. But you have to earn that attention, from the outset. So make sure that "What" (the topic) and "Why" (the value) are elements present early in the images of these moments.

Third, what is new/surprising? Once you have defined the scene and set up the tension/curiosity, deliver! Show people something that draws them beyond their common sense, their quotidian expectations, their cultural think-boundaries and into that "Aha!" moment that you had: the driving spirit or warrant of your thesis.

\section{<> What will help them remember? Last Frame.}

* You have been ordering these moments so that they flow intuitively, building from a familiar/clear base to a novel/stimulating end. What is the image that encapsulates, synthesizes, resolves your flow of moments? What pulls the story together so that it fits neatly as a whole — story, chapter, snapshot-into your audience's mind? Make that the last image.

\section{STEP 4. Finalize.}

Give people [Pencils] and [Bold-lined Markers], maybe [ㅇo잉. Now that you have a vision in mind, map out that story on the big sheet.

\section{<> Bring the frames together! Drawing a big picture.}

* Arrange your 8 sticky-note moments as you want them to flow, on your scratch paper, as a guide. Moving to your big paper, start with pencil and map out how these 8 images will flow: left-to-right? Columns? A snaking S-shape? Then trace-and-draw in more detail with ink, and add highlights of color/shading.

Take a step back and enjoy: your story, told on one page, as a clear and dynamic flow of moments. 


\section{Introduction: "Storyboarding an Interdisciplinary Learning Process"}

To make an interdisciplinary project clear to your audience, you must remember your own learning path to seeing how disciplines work together. What confused you, in each field's scholarship (ideas, techniques, terms)? What helped you make sense of those key details (e.g., examples, analogies, explanations)? And what connections did you start seeing, across those perspectives? Starting with the Main Point that you'd like to make about this topic, then trace the path of Key Moments in your learning process that lead to that point, and decide in What Order these moments should unfold to help the audience follow along your path of learning.

\section{Clear Communication through Choice of Moment \& Frame}

(Scott McCloud, Making Comics, 2006)
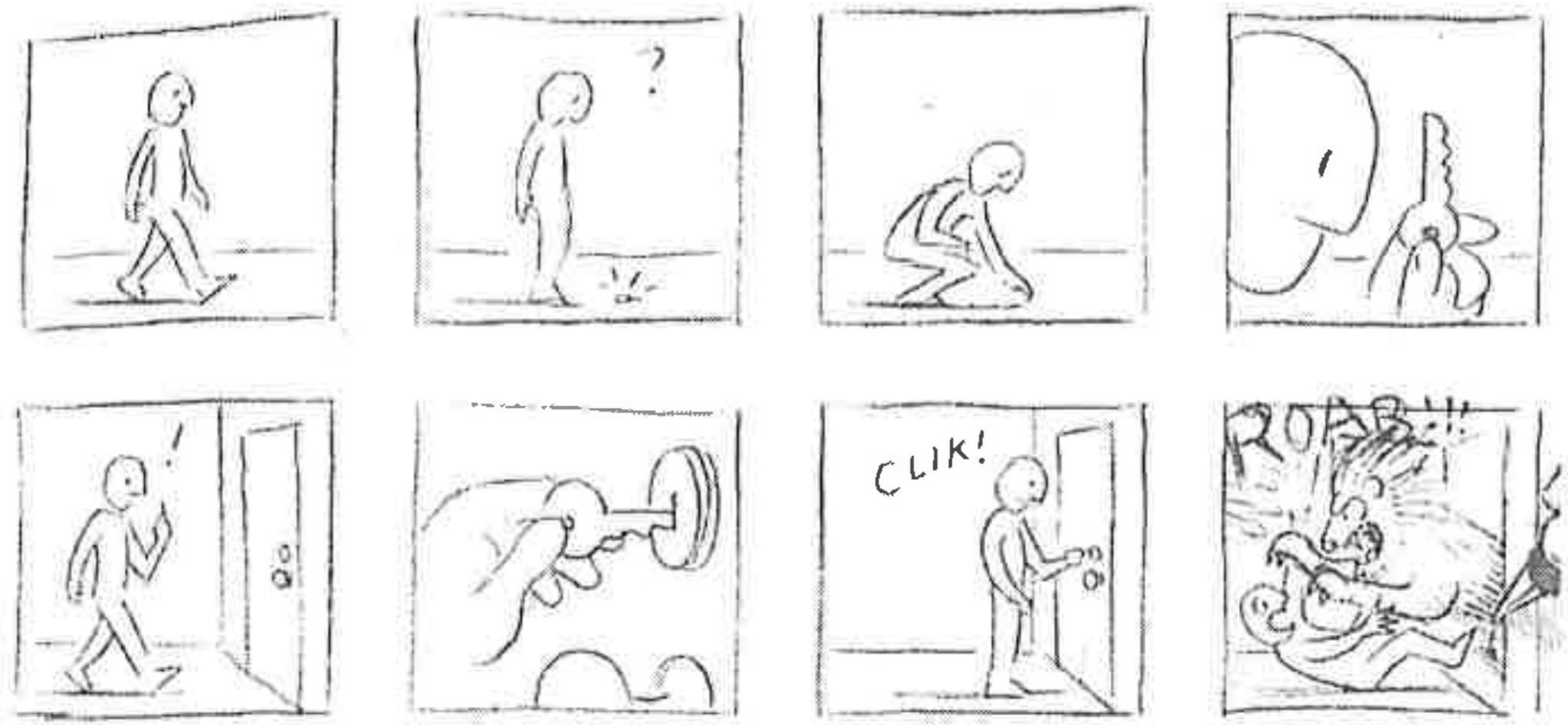

"Man is walking (1), finds key on the ground (2-4), takes it with him and then comes to a locked door (5), unlocks the door (6-7) and a hungry lion jumps out (8)."

* "Key frames" are the essential moments of a story-as-image. Once YOU identify your story's (i.e., research paper's, etc.) main point, you can look at ALL of its pieces (definitions, data, analysis, synthesis) and intentionally select those moments that are most crucial to reaching that main point: the core ideas (e.g., in crucial summary sentences and visuals) and key transitions that connect these core ideas.

* Of course, you can always add more information in, but it's important to begin here: with what is essential (i.e., take any frame away, and it changes/makes less clear the main point). 


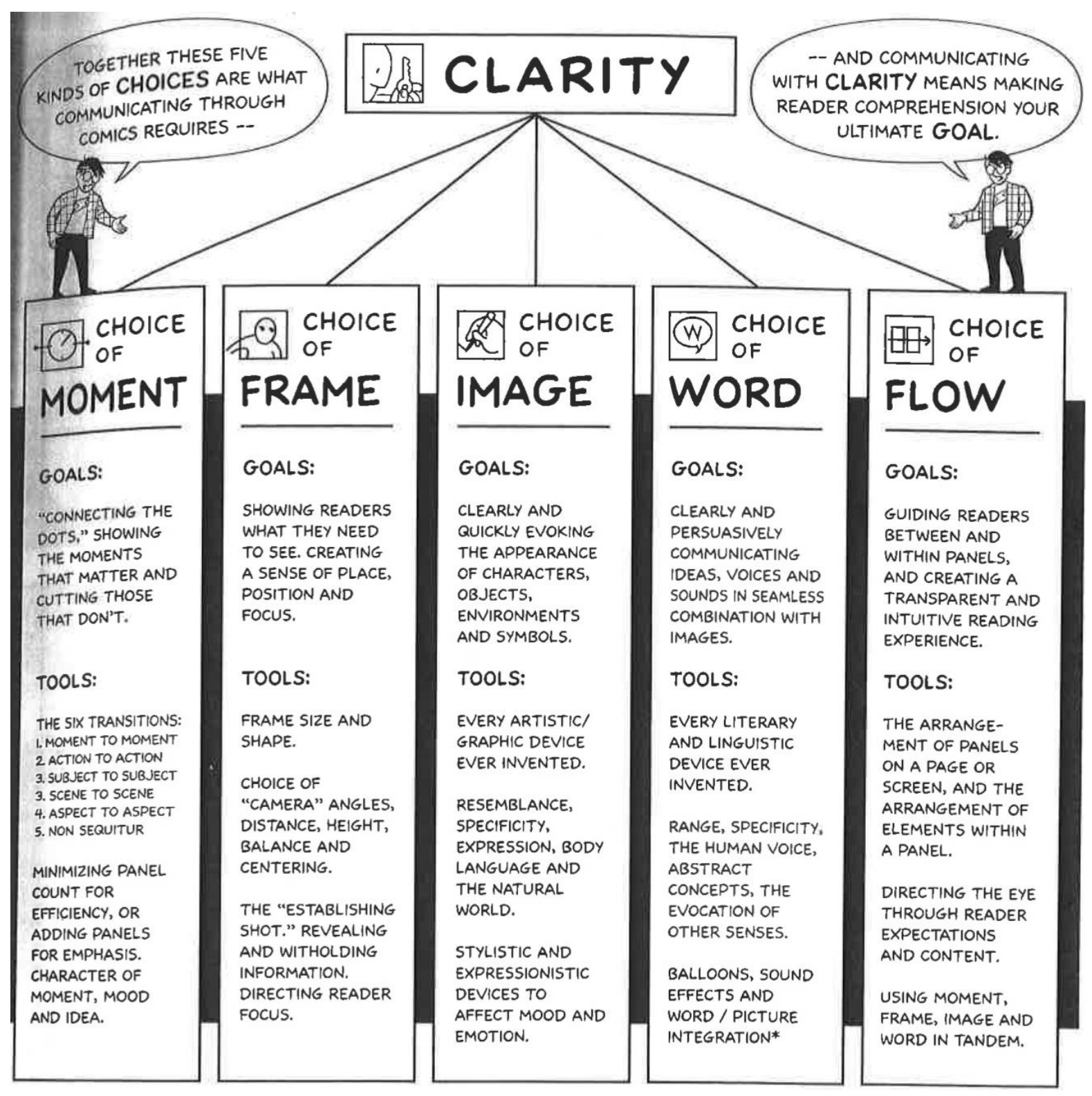

* From there, you can further improve clarity and persuasive power of your storyboard by refining your choice of Moment (remove panels for efficiency, add for emphasis), as well as Frame (change size/shape, angle/ distance, etc., to direct reader focus), Image (add detail, expression, posture, resemblance among objects), Word (adding ideas/voices/sounds), and Flow (arrangement, direction to guide viewer). 


\section{ACTIVITY STEPS: “Eight Frames" Storyboarding}

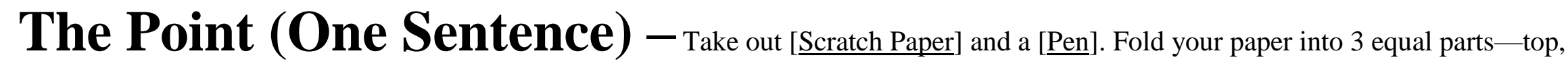

middle, bottom — and start writing about your work, in 3 stages:

<> Verbs, nouns, phrases: what *most important* terms do you need to tell your story? Write stream-of-consciousness, simple concrete, non-linear, clumped and/or scattered, all over the top $1 / 3$ of your page.

<> State the main point of your paper in 1 sentence. Start with a series of your single words and/or simple sentences: write them down, think about how they relate, and assemble them into a more complex sentence that captures your point (not the details, just the essence), in the middle $1 / 3$ of your page.

<> Summarize the story leading to that point in a stream-of-consciousness paragraph. Look at all the parts you listed, relating to the main point. Don't think! Just start writing: what is true, what is important, what have you learned? bottom 1/3.

\section{The Journey to that Point - Now everyone grab a [Large Sheet of Paper] and [Mid/Large Sticky Notes]:}

<> Prepare the story space. At the top of your large paper, copy that 1-sentence summary of your work as a guiding mantra. <> Break the story into visual moments. Read over your paragraph about that central thesis, and start illustrating key moments inside this narrative. Draw each moment on a sticky note, in whatever visual way (rely minimally on words, here).

<> Group the moments and boil them down to 8 main ones. Some of your moments may be related (first, then _; details, leading to __; this, meanwhile that __. Can you combine these moments into a more synthetic single image? Are their frames you can remove and still understand the main thesis?: narrow down your note-cards into 8 essential frames.

The Order of Frames - Now start arranging and composing your 8 key elements visually on the "big sheet.”

<> What comes first? First frame. Slip into the mindset of a learner, hearing your story the 1st time. Where do you start? <> What will keep them here? Middle frames. Time will probably guide your arranging of many frames. Consider also: What is important? (center this) What is convincing? (highlight this) What is new/surprising? (build toward this)

<> What will help them remember? Last Frame. End with an image that resolves, synthesizes, pulls the story together.

Finalize - Start with [Pencil] and map out how these 8 images will flow. Then trace-and-draw in more detail with [Bold-lined Markers], and add [Colors] to highlight. Take a step back and enjoy: your story, told on one page, as a clear and dynamic flow of moments. 


\section{Activity 10. "Interdisciplinary Principles Reflection” Synthesis Journal.}

Description: A journal meta-reflection to distill all the lessons that participants have realized about making collaborations work.

WHEN: Toward end (or before breaks) in a project, when experiences and learning are fresh. Do with participants first. Then share these anonymized insights with leaders, who can do their own reflection. WHY: To summarize patterns recognized, practical strategies learned, attitudes and ideas developed about doing interdisciplinary work.

HOW: Reflective journaling, using prior journals (activity 6) to stimulate recall, to synthesize personal experiences in the group, clarify personal take-aways, and share those perspectives with each other.

\section{STEP 1. Pick a time to Reflect.}

Periodically, at big junctures - say, right after a phase-shifting breakthrough in the project, that everyone recognized; or after the completion of a major goal—take a page to reflect on the larger arc of your progress and learning:

Pick a time and a relaxed, quiet location (a small cafe, a restaurant patio, a shaded courtyard) to meet. Prepare to bring with you, each person individually, a synthesis of your journal insights — see next steps.

\section{STEP 2. Review the Progress of Journals.}

Look back at your old entries and see how your perspective has changed (what initial ideas / attitudes / habits been reaffirmed and refined? What statements do you now look on as simplistic or inaccurate? Which observations do you see as most essentially valuable and consistently relevant in your fluency and awareness as an interdisciplinary thinker, researcher, teacher, group member?

\section{STEP 3. Write about your Learning.}

Open a blank journal-page or a [Synthesis Journal Template]. For these moments of wider-lensed reflection, invert the proportions of the previous journal pages, making more effort to:

(1) Be succinct and clear in describing the arc of concrete progress, and patterns observed there (distill your order of revelations in practice, and the path of learning/refining that you have worked through), and

(2) Spend time expanding your commentary on what works and doesn't in yours/peers' direct experiences, and principles that help you to make sense of possible reasons behind those moments of success or failure (clarifying the practical elements that worked in these particular situations, and the general ideas that might help people translate those successes in other unique, distinct interdisciplinary situations).

\section{STEP 4. Share.}

Come together as a team, to acknowledge challenges, appreciate helpful efforts, and bring together your insights by sharing these reflections - to maximize the benefit of these experiences for the group.

*The goal here is NOT for you to elucidate the ultimate, end-all-be-all truth of Interdisciplinary Research in its best possible form, but RATHER for you to name more explicitly what was true and useful for you in Learning to do IDR, personally, in specific situations.

If you have a facilitator or dedicated note-taker, collect these ideas and feedback into an [Anonymous Participant Reflections sheet] that can be shared with the group's leaders, so that they can benefit from these candid participant views - potentially using these insights to adjust the project structure, or future projects that they lead, looking forward. 


\section{Synthesis Journal Template}

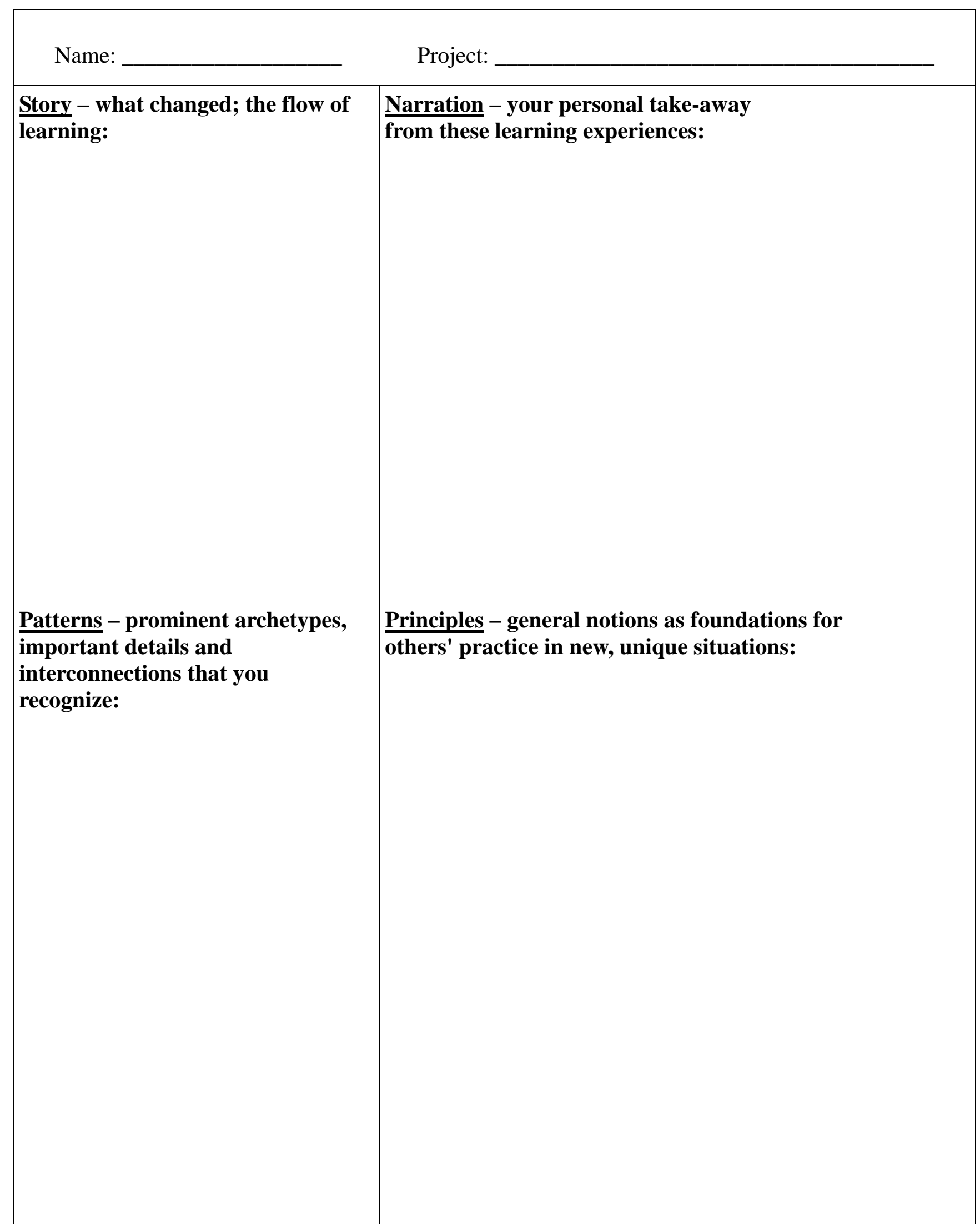




\section{Example Synthesis Journals: Grizzly Reintroduction Project}

SAMPLE 1: 6/6/2017 - Ideas from journals

- Ecologists tend to dominate the discussion, perhaps we need to step back or bring in more from other disciplines

- Don't be afraid to ask questions - what is that term, should we consider this other perspective

- Reactions from biologists to human subjects/research on humans, clear we don't feel comfortable with this - lack of understanding of methods for political science

- Make connections to different disciplines - Dr. B connecting SI methods to history (detective story, go with what you got) - talk about similarities and differences between methods

- Moments of realization that the ways of thinking are different between disciplines

- Disciplines use the same words in different ways, or they mean different things (e.g. evidence)

- Keep mind open, don't react quickly, think about it

\section{Principles:}

1. Keep your mind open - play the believing game

This is the first principle one needs to grasp if working in an interdisciplinary group, and it is certainly easier said than done. Keeping your mind open means not immediately rejecting ideas that make you uncomfortable or with which you do not necessarily agree. It is all right to feel uncomfortable; in fact, it is important to acknowledge the feeling and ask yourself why you might be feeling that way. Why does the statement the ethicist made make me feel uncomfortable? What is different about the way they are thinking from the way I think? It could help to take a moment and play the believing game: try to imagine the other person's (or discipline's) point of view and why they value that method, line of questioning, etc. This can help you understand where they are coming from and how it may be similar or different to your perspective.

2. Ask questions!

Once you have attempted to understand the other discipline's point of view, it may be that there are some unresolved questions you have about their statement, methods, or other topics. It is important to speak up and ask: "What do you consider evidence?" "How do you find your sources?" Frequently there are terms that might be unknown or used in a different way in your discipline, and for a productive discussion it may be necessary to directly ask to have those terms defined.

3. Create glossary to define terms

With a multitude of terms that are either unique to a discipline or used by disciplines in different ways, it could be helpful to put them all together into a glossary for future reference. Each time a new term comes up, or a disagreement about what a term means, add it to the glossary.

4. Talk openly about process of research (questions, methods, assumptions, etc.) and compare similarities and differences

One notable area of difference (and similarity) in our group is the methods by which disciplines pursue lines of inquiry. The grizzly group made a point of having individuals talk openly about their methods and reasoning, followed by a discussion about how those methods might be similar or different to other disciplines. It was clear from some of these conversations that there were methods that were less comfortable for certain disciplines (for example, methods of philosophers for ecologists, or methods of studying humans for ecologists). However, there were also instances where similarities were found between disciplines; for example, stable isotope analysis was compared to research in history and found to have a similar tone of detective work based around clues left behind. To productively work together as an interdisciplinary research group, we must have an understanding of how the different disciplines go about asking questions, finding answers, and interpreting those answers. To do so, it is important to openly discuss the process of research of each discipline.

5. If one discipline encompasses the majority of the group, be aware of the other perspectives

Finally, in a situation where there are a large number of individuals from one discipline (in our case, ecology/environmental science), it is important for those individuals to be aware that there are other perspectives in the room. It may be necessary to take a step back to allow other voices to be heard, or to directly ask the opinion of other disciplines if there is a concern that their perspective hasn't been heard. I saw this done well and done poorly in our group, and we are more likely to have a truly interdisciplinary discussion when each person is aware of their discipline's need to step up or step back. 


\section{Sample 2: Big Reflection/Distillation toward better Teaching Practices:}

Based on my experiences this year in the Grizzly group and in the GRAD210 Pedagogy course, I feel that I have better insight into, and am equipped with a more robust toolkit in order to understand, educational dynamics and communication dynamics within an academic setting. My big takeaway (possible pedagogical value), and its attendant facets/explanations/sub-takeaways/sub-values, from these experiences can be distilled as such:

1. Be able to read the room/know your audience/be responsive to changing classroom situations while still remaining "true to yourself" as a person, student, researcher, mentor/mentee, educator, etc..

a. Anticipate and embrace (helpful) discomfort as this might indicate people grappling with threshold concepts. Be open to having open dialogue so people can talk out/explain what they're having trouble with, ask questions, verbalize their feelings, etc.

b. Try to be aware of when and in what ways one might have "disciplinary blinders" on. Relatedly, even if not "disciplinary" per se, be aware of what your vested interest is in the topic being discussed — what's your dog in the fight? Are you interacting in a way that might not be helpful/productive/the best use of time because you are specifically invested in this subject/person? Do you treat speakers equally? Should you?

c. We all (can) learn together $\rightarrow$ we learn by interacting with others; a learning environment never has to be a one-way street or a zero-sum game.

d. Cognitive and affective domains are often inextricable in learning settings, perhaps even more so in interdisciplinary/multidisciplinary settings. Humor and humility is a great olive branch/bridging element.

e. Be aware that people are only human - we are all in some way prone to the frailties, inconstancies, vulnerabilities, etc. of the human condition. Be mindful of what people pay attention to and why they might pay attention to it. Similarly, be aware of what you pay attention to and why you might pay attention to itthinking this through might help elucidate some hidden biases in yourself that you were previously unaware of. Understanding your own biases can help you mitigate or eliminate these biases, thus making you a more constant and effective teacher.

\section{Sample 3: Overall take away from Journaling about Grizzly Seminar Spring Quarter 2017:}

I especially enjoyed the speakers on black bears. I think this is because they seemed the most realistic and down-to-earth. They understand the interdisciplinary notion of conservation. They do not label themselves as just ecologists and biologists, they are writers of children's books, they are educators, they have been around conservation for so long they "get it". Conservation is not an academic discipline used to further one's career but a never ending attempt to push the world to be more sustainable. Its emotional, its challenging, it involves community and it goes far beyond and outside Academia.

Education is something necessary before, during, and after reintroduction projects. Education is communication. It is the skillful exchange and discourse of knowledge, information, ideas, values, and desires which outline the nature of our lives together on this planet. It is not an after-the-science-is-done thing.

My biggest take away from my journals is that I believe grizzly reintroduction and projects like it will not work with the type of scientists who thinks science is tops or even that academia is tops. It will not work with people who think social science methods are just some qualitative bullshit. Many scientists do not even know what social science is yet they think their science methods are superior. These assumptions I see scientists make are NOT SCIENTIFIC!!!

Educators think analytically about how to interact and how important that interaction is allllll thhheee timmmmme. We pick up on power dynamics and work to dismantle them as they are occurring. We embrace conflict, disagreement, and are generally looking to better the world. Applied Academia, you can call it.

On a similar note, why the hell have we not consulted indigenous groups about their opinion? I have suggested it to Dr. X, Y, and Z a few times. We have some ancient wisdom right here in our backyard within the Chumash Band. Chumash, a people who managed to live peacefully without killing off grizzly bears for thousands of years. There is always some excuse that sounds something like "Academics know best". That is NOT CRITICAL THINKING! Indigenous lands around the world represent some of the most biodiverse land on the planet. In other words, most of the remaining primary forest habitat is owned and preserved by indigenous groups. As an example, the first nation people in and around Princess Island off the coast of BC, where the spirit bear lives, have exhibited some of the most profound bear conservation and stewardship ever known yet somehow they are not experts... why? Because they are not mainstream? Or is it because they are not white? Is it because they do not gloat about their knowledge in science journals? My journal entries reflect that I am concerned about all this and I guess I am the jerk that is saying something. 